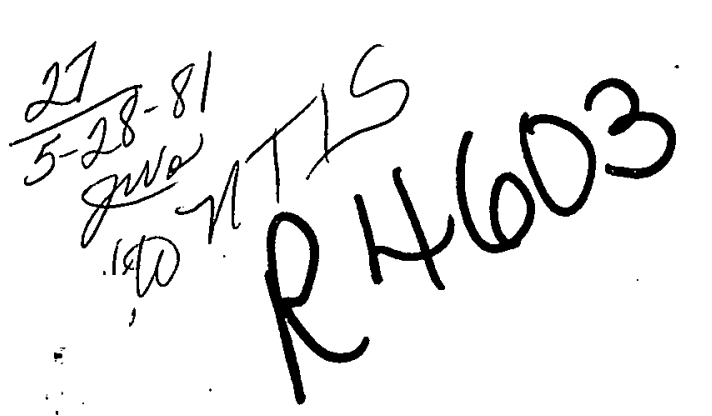

(1)

BDX-613-2483

\title{
Speed and Pressure Control System Design and Simulation for a Compression Press
}

By R. H. Floersch

Published April 1981

Topical Report

Prepared for the United States Department of Energy Under Contract Number DE-ACO4-76-DP00613.

\section{Bendix/ Kansas City \\ Division}




\section{DISCLAIMER}

This report was prepared as an account of work sponsored by an agency of the United States Government. Neither the United States Government nor any agency Thereof, nor any of their employees, makes any warranty, express or implied, or assumes any legal liability or responsibility for the accuracy, completeness, or usefulness of any information, apparatus, product, or process disclosed, or represents that its use would not infringe privately owned rights. Reference herein to any specific commercial product, process, or service by trade name, trademark, manufacturer, or otherwise does not necessarily constitute or imply its endorsement, recommendation, or favoring by the United States Government or any agency thereof. The views and opinions of authors expressed herein do not necessarily state or reflect those of the United States Government or any agency thereof. 


\section{DISCLAIMER}

Portions of this document may be illegible in electronic image products. Images are produced from the best available original document. 
This report was prepared as an account of work sponsored by the United States Government. Neither the United States nor the United States Department of Energy, nor any of their employees, nor any of their contractors, subcontractors, or their employees, makes any warranty, express or implied, or assumes any legal liability or responsibility for the accuracy, completeness or usefulness of any information, apparatus, product or process disclosed, or represents that its use would not infringe privately owned rights.

Printed in the United States of America

Available From the National Technical Information Service, U.S. Department of Commerce, 5285 Port Royal Road, Springfield, Virginia 22161.

Price: Microfiche \$3.00

Paper Copy $\$ 5.25$ 
$\mathrm{BDX}-613-2483$

Distribution Category UC-38

\begin{abstract}
SPEED AND PRESSURE CONTROL SYSTEM
DESIGN AND SIMULATION FOR A COMPRESSION PRESS
\end{abstract}

By R. H. Floersch

Published April 1981

Topical Report

R. H. Floersch, Project Leader

Project Team:

C. E. Gaynor

D. R. Hahn

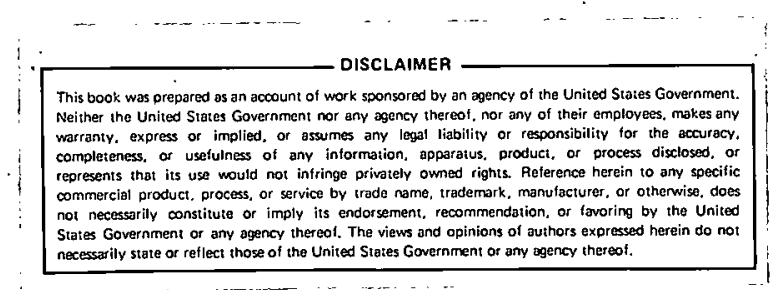


SPEED AND PRESSURE CONTROL SYSTEM DESIGN AND SIMULATION FOR A COMPRESSION PRESS

BDX-613-2483 Topical Report, Published April 1981

Prepared by R. H. Floersch

A new system design using closed loop control on the hydraulic system on compression transfer presses used to make filled elastomer parts will improve accuracy and repeatability of speed and pressure control during critical pre-cure forming stages. The present open loop system does not provide the control necessary to mold repeatably the filled elastomer products. These products form with great difficulty because of high loading levels of filler materials. The new system will mean improved wall thickness and control of loaded elastomer parts, thus reducing the amount of scrap caused by wall thickness variations.

$\mathrm{DK} / \mathrm{js}$

This report was prepared as an account of work sponsored by the United States Government. Neither the United States, nor the United States Department of Energy, nor eny of their employees. nor any of their contractors. subcontractors, or their employees. makes any warrenty, expressed or implied or assumes any legal lisbility or responsibility for the accuracy. completeness or usefulness of any information. apperatus. product, or process disclosed, or represents that its use would not infringe privately owned rights.
The Bendix Corporation

Kansas City Division

P. O. Box 1159

Kansas City, Missouri 64141
A prime contractor with the United States Depertment of Energy under Contract Number DE-AC04-76-DPOO613 
CONTENTS






\section{ILLUSTRATIONS}

Figure

Page

1

Compression Molding Machine With Ram Extended (P105120). . . . . . . . . . .

Compression Machine Hydraulic Circuit (Current). . . . . . . . . . . . . .

Current Hydraulic Speed . . . . . . . . . .

Preform Cross-Sectional Change During Molding . . . . . . . . . . . . . • . •

Closed Loop Hydraulic speed Control Circuit With Flow Control Valve. . . . .

General Block Diagram of Ram Velocity Control. . . . . . . . . . . . . . . .

Load Pressure Versus Spool Position From Equation 22. . . . . . . . . . . . . .

Typical Pressure Profile With Degas . . . .

Hydraulic Circuit With Flow Control Servovalve... . . . . . . . . . .

General Block Diagram of Press Hydraulic Control System. . . . . . . . .

General Block Diagram of Hydraulic Speed Control System. . . . . . . . . . .

Closing Speed Control Circuit . . . . . . .

Pressure Control Circuit. . . . . . . . . . . 


\section{TABLES}

Number

1

2
Hydraulic Radius for Increasing Time . . . .

Proportional Gain for Various

Potentiometers . . . . . . . . . . . . .
Page

18

37 
SUMMARY

Open loop control of the hydraulic system on compression transfer presses used to make filled elastomer parts for years has been sufficient for molding free-flowing materials not appreciably susceptible to variations in forming speed or cure pressure. Fillers at high loading levels added to an elastomer matrix hinder the flow. The flow problem becomes more difficult if the material must flow through a small cross-sectional area. Highloading levels and thin cross sections are typical of loaded elastomer parts.

The current hydraulic speed control system design results in a maximum initial ram speed that drops to zero during forming. This curved path depends on material flow properties and distribution within the mold. Repeatability of the forming operation within the existing hydraulic system cannot exist.

However, a new system design that uses closed loop control of the hydraulic system will improve accuracy and repeatability of speed and pressure control during the critical forming stages before part cure. This system will mean improved wall thickness and configuration control of loaded elastomer parts.

Closed loop hydraulic control will provide accurate, constant, and repeatable velocity and pressure control, up to the pressure transition point, by monitoring and correcting deviations from set point during the cycle and from cycle to cycle. Accuracies of \pm 1 percent $(26.69 \mathrm{kN})$ from set point during steady operation and less than 1 percent repeatability are expected.

The frequency response of the final control elements is critical for system settling time and overshoot requirements. Poor frequency response characteristics can cause instabilities that

translate into unpredictable oscillating responses to disturbance or set point changes.

In the new design, a flow control valve manipulates flow during speed control and pressure during load control. The frequency response of the valve enables it to travel from full closed to full open to full closed 16 times each second.

The closing speed control cycle has two segments: fast close, using only the booster ram, and slow close, using the main ram area. A gain change is required in the closed loop speed circuit to compensate for the speed change, a 15 to 1 reduction. After closing, a pressure control circuit is required to maintain the desired pressing force. The opening speed circuit also has two segments: slow opening for part stripping, and fast opening to 
return the ram to starting position. The entire cycle is composed of two closing speed circuits, a pressure circuit, and two opening speed circuits. The set points for those analog circuits and additional machine logic functions will be controlled by a microprocessor.

The internal electrical circuitry of the machine logic will allow both closed loop control and reversion to existing manual control. An additional option designed into the control circuitry allows constant ram speed control up to a variable transition pressure. After alteration the control mode will appear unchanged to the users.

One hypothesis proposes that flow mechanisms of the non-Newtonian filled elastomer may parallel Newtonian fluids in the laminar region; that is, higher flow rates result in lower friction factors. Conversely, as the flow rate decreases, the friction factor increases, requiring more pressure to cause motion. No means at Bendix exists to evaluate the hypothesis, because no constant speed variable pressure devices in the range of the molding machine exist. If the hypothesis is correct, the traditional molding concepts used at Bendix will be altered appreciably, which could reduce drastically the amount of scrap caused by wall thickness variation.

The speed control circuit was simulated on a digital computer to determine control modes and magnitudes of various gains. The simulations indicate that the integral mode is mandatory for minimum steady state error and for minimum settling time after the speed transition. Load control simulation is extremely difficult and highly dependent on the machine, because the flow requirements are dependent on valve leakage, which will vary among machines. 


\section{DISCUSSION}

\section{SCOPE AND PURPOSE}

The intent of implementing closed loop control of the machine hydraulic system is to reduce the amount of scrap caused by wall thickness and by configuration of filled elastomers. Ram speed and pressure control currently are being accomplished open loop, through inaccurate and non repeatable methods. A microprocessor/ analog closed loop control system will be designed, implemented, and tested to determine whether closed loop control improves part quality.

\section{ACT IV ITY}

\section{Current System Functional Description}

Figure 1 shows a compression molding machine with the ram extended. The hydraulic circuit for the press is illustrated in Figure 2. The operator starts the molding cycle by energizing solenoids $A, K K$, and $D$, which causes pumps P1 and P2 to deliver fluid to the booster ram area $\left(D_{b}\right)$.

Closure speed is governed by the amount of fluid allowed to bleed back to the tank through solenoid $D$ and flow return valve $F_{2}$. The ram closes quickly because both pumps are delivering approximately $0.0029 \mathrm{~m} 3 / \mathrm{s}$ ( $46 \mathrm{gal} / \mathrm{min}$ ) of fluid into a relatively small, cross-sectional area $\left(D_{b}\right)$ of the ram. A slow-down limit switch causes solenoid $M$ to energize, redirecting the fluid to both the main ram $\left(D_{m}\right)$ and booster ram $\left(D_{b}\right)$ cross sections, and significantly increasing the effective cross-sectional area.

The steady-state ram speed can be calculated from the following:

$\mathrm{V}_{\mathrm{r}}=\frac{\mathrm{Q}_{\mathrm{r}}}{\mathrm{A}_{\mathrm{r}}}$

where

$\mathrm{V}_{\mathrm{r}}=\operatorname{ram}$ velocity $(\mathrm{m} / \mathrm{s})$;

$Q_{r}=$ hydraulic fluid flow rate into the ram area $\left(\mathrm{m}^{3} / \mathrm{s}\right)$; and

$A_{r}=$ ram cross-sectional area $\left(m^{2}\right)$.

The ram slow-down is accomplished by increasing significantly the ram area from $12645 \mathrm{~mm}^{2}$ (19.6 in.2) to $192677 \mathrm{~mm}^{2}$ (298.6 in.2), 


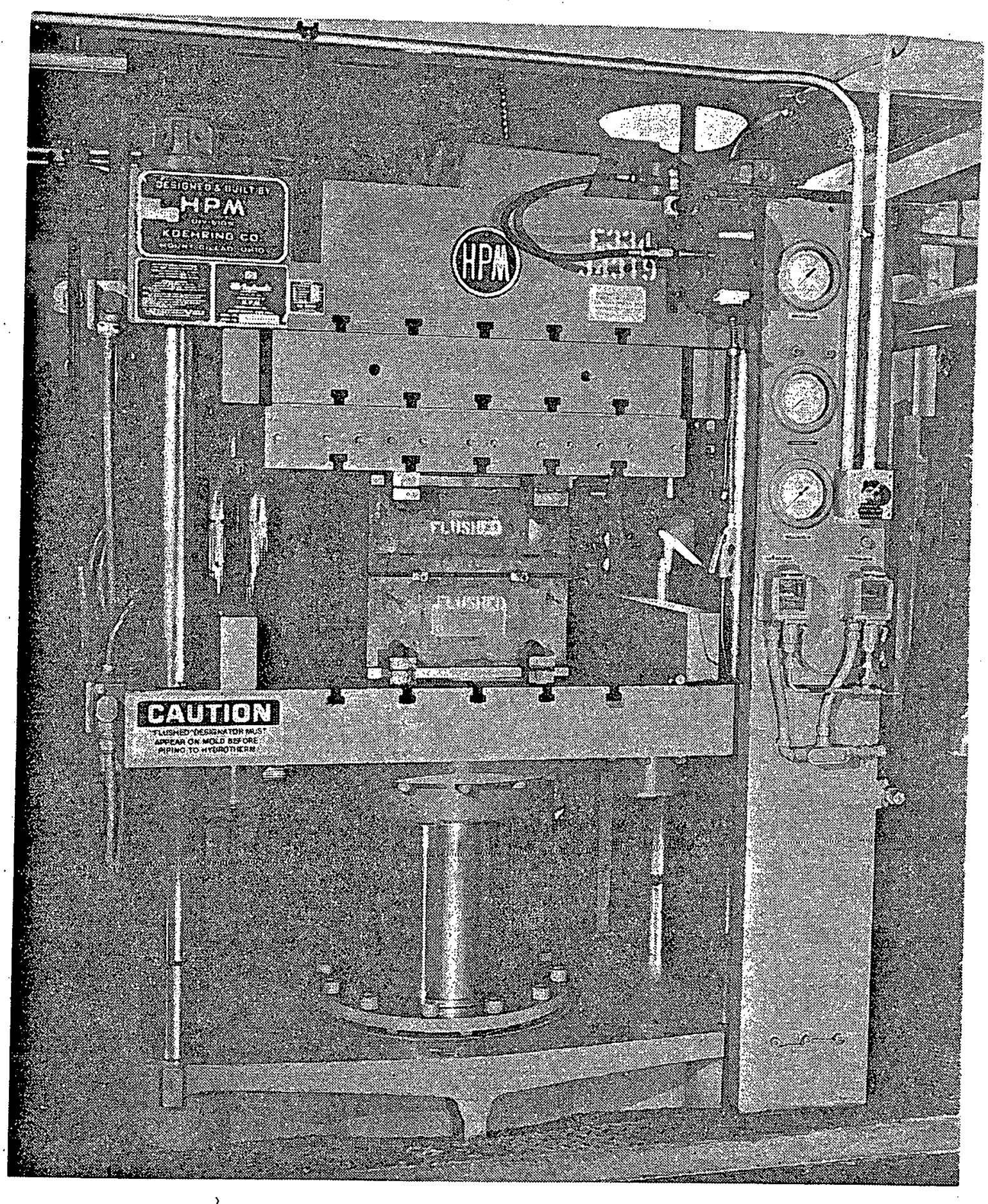

Figure 1. Compression Molding Machine With Ram Extended 
which amounts to a 15-fold increase in area, or for the same volume flow rate, a 15-fold decrease in ram speed. The flow rate $Q_{r}$ can be manipulated to reduce or increase the ram speed by varying the opening diameter of flow return valve $\mathrm{FRV}_{1}$ or $\mathrm{FRV}_{2}$, depending upon the slow-close limit switch activation.

The slow-close limit switch usually is set from $2.54 \mathrm{~cm}$ ( 1 in.) to $7.62 \mathrm{~cm}$ ( $3 \mathrm{in.}$ ). from mold closure. Solenoid $\mathrm{D}$ de-energizes and solenoids $M$ and $C C$ energize at slow-close switch activation. The speed drops immediately to the pressing (forming) speed. The line pressure $\mathrm{P}_{\ell}$ increases as the molding material contacts the punch and starts to flow. The increase in line pressure is a function of flow resistance of the material in the mold. That resistance is a function of material viscosity, the shear rate, the contact area, and rate of crosslinking.

In all further discussions, the rate of crosslinking is assumed slow enough to be neglected as a variable.

As line pressure reaches $2294 \mathrm{kPa}$ ( $333 \mathrm{psi}$ ), equivalent to $444.8 \mathrm{kN}$ ( 50 tons) of molding force, the machine switches from velocity to pressure control by de-energizing solenoids KK and CC. The system flow rate drops to $0.005 \mathrm{~m} / \mathrm{s}$ ( $8 \mathrm{gal} / \mathrm{min}$.) to maintain the required pressure remotely regulated by an electrically actuated relief valve (MRV in Figure 2).

To achieve a specified cure force the machine operator adjusts a potentiometer while observing a Bourdon pressure gage calibrated in force units. The operator holds the ram force constant until the specified cure time has elapsed. Then the operator reduces the pressure to $2294 \mathrm{kPa}$. The operator activates an open switch, which causes solenoids $B$ and $S$ to energize, directing as much as $0.0005 \mathrm{~m}^{3} / \mathrm{s}$ of hydraulic fluid to the top of the ram. The ram is held in place under no positive pressure by the counter-balance valve (CBV in Figure 2), which is adjustable and is set simply to hold the ram and mold weight. The counterbalance valve allows fluid out of the booster ram area when an opposing force greater than the ram and mold is applied to the top area of the ram through the hydraulic fluid. Stripping speed is controlled by the amount of hydraulic fluid allowed to return to the tank through the flow return valve $\mathrm{FRV}_{3}$ in Figure 2 . A fast-open limit switch is energized after the mold has traveled approximately $5.5 \mathrm{~cm}$. This action de-energizes solenoid $\mathrm{S}$ and energizes solenoid $\mathrm{KK}$, delivering the full $2.9 \times 10^{-3} \mathrm{~m}^{3} / \mathrm{s}$ to the ram top, causing it to open at maximum speed. A stop-limit switch deactivates solenoid $B$, which diverts the supply fluid to the tank and stops the ram.

In summary, the cycle steps are these: fast-close with a transition to slow-close; slow-close while forming with a transition 


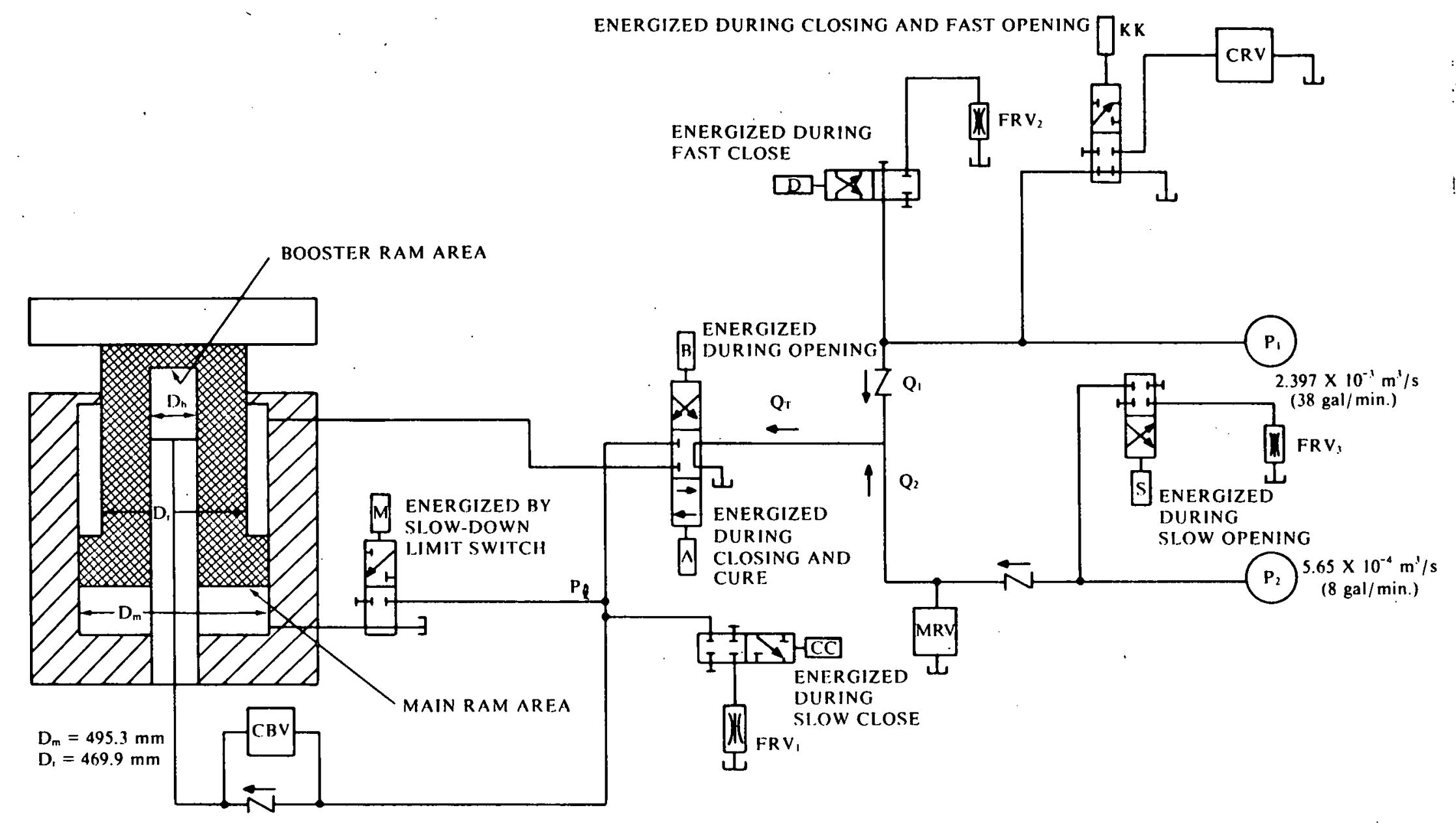

Figure 2. Compression Machine Hydraulic Circuit (Current) 
to load control; load control with final mold closure and a minimum 20-minute cure time; load relaxation with transition to stripping speed control; stripping speed control to fast-open transition, and fast-open to slow-down and stop.

For process consistency, any control system implemented must consist of the same basic steps: speed control, load control, speed control.

\section{Closed Loop Control}

As previously indicated, each of the speed control cycles has a fast-open/close segment and a slow open/close segment. The fastopen/close segments are the least important segments. The fastclose travels the majority of the ram stroke as quickly as possible, without upsetting the loose material in the mold cavity. during the initial acceleration and the transition deceleration. The fast-open only returns the ram to the start position as quickly as possible. The slow-close segments are the important speed segments, and the most important portion of the speed cycle where the initial part formation occurs. If the resistance to movement of the molding compound is minimal, resulting in line pressures less than $2298 \mathrm{kPa}$ (333 psi) to sustain motion, then the entire part formation will occur in the slow-close mode. The line pressure will exceed the $2298 \mathrm{kPa}$ transition pressure when the two mold halves touch, or when the resistance to flow of mold compound is high and requires more energy to sustain motion.

The slow-close ram velocity is controlled currently by bleeding a portion of the fixed flow rate back to the tank through a variable opening valve. The hydraulic pumps are positive displacement that deliver either $2.9 \times 10^{-3} \mathrm{~m}^{3} / \mathrm{s}$ (46 gal/min), if both are in the circuit, or $0.5 \times 10^{-3} \mathrm{~m}^{3} / \mathrm{s}$ ( 8 gal/min) when only the lowvolume pump is operating. Equation 1 indicates that the ram velocity is directly proportional to the volumetric flow rate coming into the ram area and inversely proportional to the ram area itself. To achieve the slowdown transitions, the ram area is altered from the booster area only to the main and booster ram areas. The maximum fast-close speed is developed when both pumps are delivering their rated capacities into the booster area.

$\mathrm{v}_{\mathrm{r}}=\frac{2.9 \times 10^{-3} \mathrm{~m}^{3} / \mathrm{s}}{1.26 \times 10^{-2} \mathrm{~m}^{2}}=0.23 \mathrm{~m} / \mathrm{s}$

The maximum ram velocity after slow-down, when the same volumetric flow rate is being directed at the main ram area, is 
$\mathrm{v}_{\mathrm{r}}=\frac{2.9 \times 10^{-3} \mathrm{~m}^{3} / \mathrm{s}}{0.1927 \mathrm{~m}^{2}}=0.015 \mathrm{~m} / \mathrm{s}$

Shifting the area achieves a 15-fold decrease in speed. The speed within each segment is controlled by bleeding a portion of the $2.9 \times 10^{-3} \mathrm{~m}^{3} / \mathrm{s}$ back to the tank. Figure 3 illustrates the speed circuit schematically.

A mass balance from Figure 3 for a constant hydraulic fluid density results in:

$Q_{r}=Q_{p}-Q_{t}$

where

$Q_{r}=$ volumetric flow into ram area $\left(\mathrm{m}^{3} / \mathrm{s}\right)$,

$Q_{p}=$ total volumetric flow $\left(\mathrm{m}^{3} / \mathrm{s}\right)$, and

$Q_{t}=$ volumetric flow returning to $\operatorname{tank}\left(\mathrm{m}^{3} / \mathrm{s}\right)$.

The flow rate returning to the tank can be calculated from

$Q_{t}=C_{v} \sqrt{\frac{P_{\ell}-P_{t}}{\rho}}$

where

$\mathrm{C}_{\mathrm{v}}=$ valve flow coefficient $\left(\mathrm{m}^{3} / \mathrm{s}-\mathrm{kPa}\right)^{1 / 2}$

$\mathrm{P}_{\ell}=$ line pressure $(\mathrm{kPa})$,

$P_{t}=\operatorname{tank}$ pressure $(\mathrm{kPa})$, and

$\rho=$ hydraulic fluid specific gravity.

The flow coefficient in Equation 5 is a function of the opening that can be manually adjusted, but once set usually is not altered. The tank pressure generally is ambient; therefore, Equation 5 becomes

$Q_{t}=C_{v} \sqrt{\frac{P_{\ell}}{\rho}}$

For a fixed opening $\left(C_{v}\right)$, the flow rate returning to the tank is a function of only the line pressure. That pressure, developed in the hydraulic line, is a function of the moving mass and the flow resistance of the molding material. The line pressure required to move the ram and mold mass is minimal (less than $69 \mathrm{kPa})$; therefore, any line pressure buildup before mold closure 


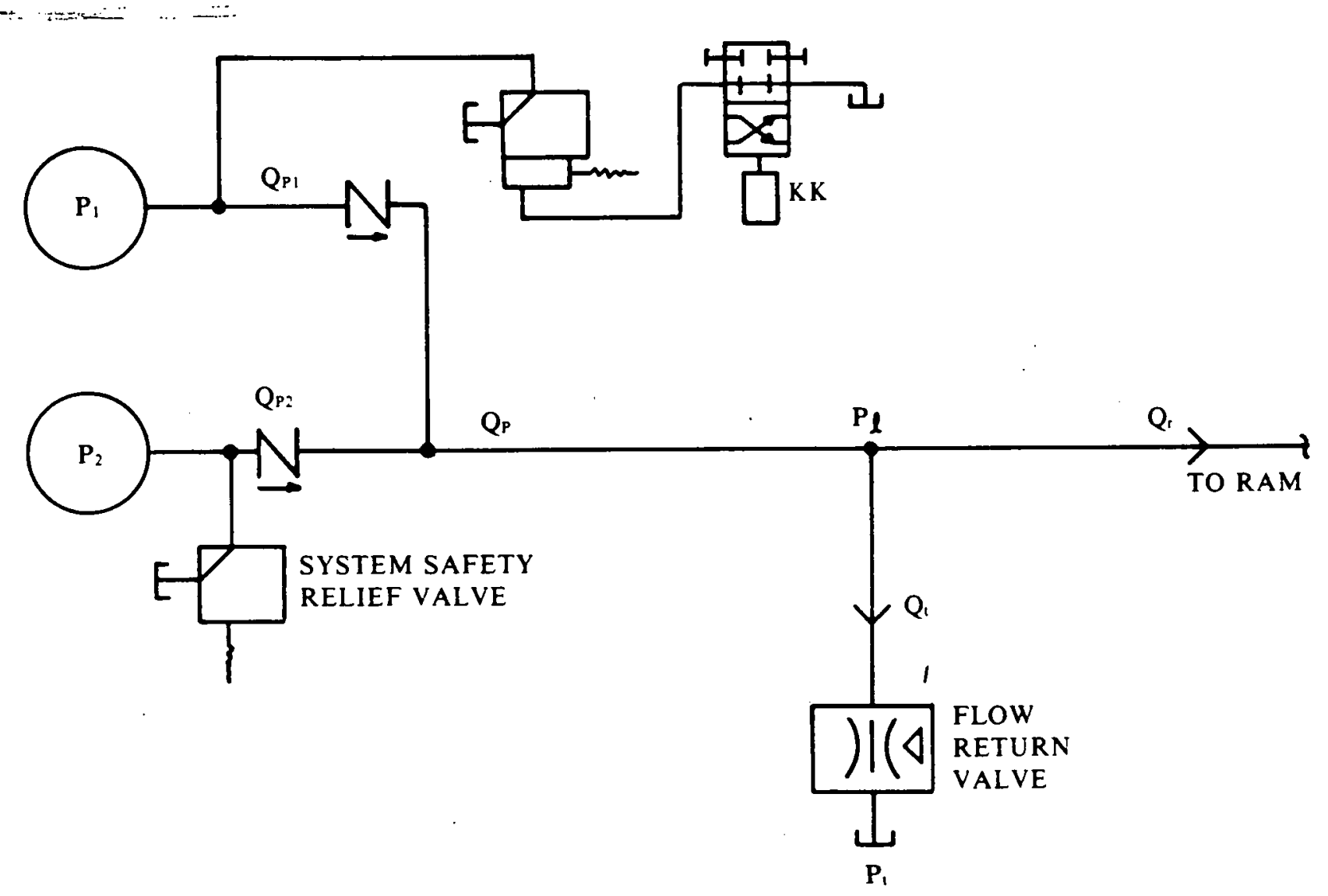

Figure 3. Current Hydraulic Speed

is predominantly a function of the forming resistance of the material.

Figure 4 illustrates a fictitious part preform cross section of unit depth at different forming operation stages. The hydraulic radius is used in Newtonian flow as one indicator of the resistance to flow. That is, a large hydraulic radius represents less resistance to flow than a small hydraulic radius for the same set of conditions. The hydraulic radius is defined as the crosssectional area divided by the wetted perimeter.

$R=\frac{\text { cross-sectional area }}{\text { wetted perimeter }}$

For the cross section represented in Figure 4 , the hydraulic radius is

$$
R t=\frac{x(t) D(t)}{2[x(t)+D(t)]}
$$


A. INITIAL



B. INTERMEDIATE



C. FINAL

Figure 4. Preform Cross-Sectional Change During Molding

The volume of the preform $\left(V_{m}\right)$ in Figure 4 is a function of the mass of material $\left(M_{m}\right)$ and the density $\left(\rho_{m}\right)$.

$v_{m}=\frac{M_{m}}{\rho_{m}}$

Because no mass is being added during forming, the volume is constant if the density is constant. The volume of the preform for unit depth is

$\mathrm{V}_{\mathrm{m}}=\mathrm{X}(\mathrm{t}) \mathrm{D}(\mathrm{t})$

The numerator of Equation 8 can be replaced with Equation 10:

$R(t)=\frac{V_{m}}{2[X(t)+D(t)]}$

The hydraulic radius magnitude during forming, as indicated by Equation 11 , is a function of only the wetted perimeter. The wetted perimeter is a time function of the dimensions $X$ and $D$. The thickness for a constant ram velocity is

$x(t)=x_{0}-v_{r} t$

where 
$\mathrm{X}_{\mathrm{O}}=$ initial preform thickness $(\mathrm{m})$,

$\mathrm{v}_{\mathrm{r}}=$ ram velocity $(\mathrm{m} / \mathrm{s})$, and

$t=\operatorname{time}(s)$.

The volumetric flow rate of the material

$\frac{d V_{m}}{d t}=\frac{\partial V_{m}}{\partial D} \frac{\partial D}{\partial t}$

for a constant ram velocity. To determine $D$ as a function of time, Equation 12 is substituted into Equation 10.

$D(t)=v_{m}\left(x_{0}-v_{r} t\right)^{-1}$

and the partial of Equation 14, with respect to time, is developed.

$$
\begin{aligned}
\frac{\partial D}{\partial t} & =(-1) v_{m}\left(x_{o}-v_{r} t\right)^{-2}\left(-v_{r}\right) \\
& =\frac{v_{r} v_{m}}{\left(x_{0}-v_{r} t\right)^{2}}
\end{aligned}
$$

Taking the partial of $\mathrm{V}$ with respect to $\mathrm{D}$ in Equation 10,

$\frac{\partial V}{\partial D}=X(t)=\left(X_{0}-V_{r} t\right)$

Substituting Equations 15 and 16 into Equation 13,

$$
\frac{d V}{d t}=\frac{V_{r} V_{m}}{\left(X_{0}-V_{r} t\right)}
$$

Equation 17 indicates that the volumetric flow rate increases as the mold closes, because the numerator is constant and the denominator is decreasing as a function of time. Substituting Equations 12 and 14 into Equation 11 after rearrangement results in an expression of the hydraulic radius as a function of time:

$$
R(t)=\frac{v_{m}\left(x_{o}-v_{r} t\right)}{2\left[\left(x_{o}-v_{r} t\right)^{2}+v_{m}\right]}
$$


Table 1 lists the hydraulic radius as a function of time for these conditions:

$$
\begin{aligned}
& \mathrm{X}_{\mathrm{o}}=0.254 \mathrm{~m} \\
& \mathrm{v}_{\mathrm{m}}=0.0819 \mathrm{~m}^{3} \\
& \mathrm{v}_{\mathrm{r}}=0.0635 \mathrm{~m} / \mathrm{s}
\end{aligned}
$$

Table 1 indicates that as the mold closes, the hydraulic radius becomes smaller, requiring more energy to sustain a constant flow rate. However, Equation 17 indicates that the volumetric flow rate is not remaining constant but increasing as the mold closes, and the hydraulic radius is decreasing, requiring a substantial increase in energy. The only way to increase the hydraulic energy input to the ram for a fixed volume flow rate $\left(Q_{r}\right)$ is to increase the pressure.

$\mathrm{HE}=1000 \mathrm{Q}_{\mathrm{r}} \mathrm{P}_{\ell} ;$

where

$\mathrm{HE}=$ hydraulic energy (W),

$Q_{r}=$ ram volume flow rate $\left(\mathrm{m}^{3} / \mathrm{s}\right)$, and

$\mathrm{P}_{\ell}=$ Iine pressure $(\mathrm{kPa})$.

The flow rate returning to tank increases as line pressure increases, as indicated by Equation 6 for bleed speed control systems.

The flow rate to the ram area must decrease, as indicated by Equation 4 , if the return flow rate to the tank increases. A corresponding decrease in ram velocity occurs, as indicated by Equation 1. The ram velocity is not constant in the current system; therefore, Equations 12 through 18 do not depict accurately the actual conditions. Equation 12 must be modified to include an acceleration term. However, the general relationships still hold. The acceleration term would reflect the resistance of the material to flow, because, if there were no resistance, the ram velocity would remain constant until the mold halves touched. The magnitude of that acceleration term never has been measured; consequently, the derivations showing its effect on the velocity decrease are academic.

Generally, for filled elastomers, when resistance first is encountered, the line pressure builds up rapidly until a pressure switch activates initiating transition from open loop velocity control to open loop pressure control. Pressure is remotely 
Table 1. Hydraulic Radius for

Increasing Time

\begin{tabular}{ll}
\hline $\begin{array}{l}\text { Time } \\
(\mathrm{s})\end{array}$ & $\begin{array}{l}\text { Hydraulic Radius } \\
(\mathrm{m})\end{array}$ \\
\hline 0 & 0.031 \\
1 & 0.0286 \\
2 & 0.0249 \\
3 & 0.0179 \\
\hline
\end{tabular}

controlled by adjustment of a potentiometer changing the poppet tension on valve MRV in Figure 2. The line pressure generally must be increased more than $9100 \mathrm{kPa}(55000 \mathrm{~N}$ force) before the mold halves close.

Equations 12 through 18 are valid for the proposed new closed loop system, because ram velocity will be a controlled variable maintained constant. Figure 5 illustrates schematically the new flow circuit. Flow $\left(Q_{r}\right)$ will be controlled to maintain ram velocity $\left(V_{r}\right)$, letting pressure $\left(P_{\ell}\right)$ float up to either the pressure transition point or to the setting of the pressure relief valve (MRV).

In Figure 5, the old pressure relief valve (MRV), set at $13790 \mathrm{kPa}$, will be used to control the upstream pressure to the flow control valve. The flow rate $\left(Q_{r}\right)$ through the new flow control valve is

$Q_{r}=C_{v}{ }^{i}\left(P_{S}-P_{\ell}\right)^{1 / 2}$

where

$C_{V}=$ valve flow coefficient,

$i_{S}=$ valve spool position proportional to input current,

$\mathrm{P}_{\mathrm{S}}=$ upstream or supply pressure, and

$P_{\ell}=$ load pressure.

To maintain constant ram velocity as indicated in the preceding analysis, the load pressure must increase. To maintain a constant flow rate to the ram, the spool current must increase as the load pressure increases, which will be accomplished under feedback control. Figure 6 illustrates the general block diagram for the speed control circuit. 


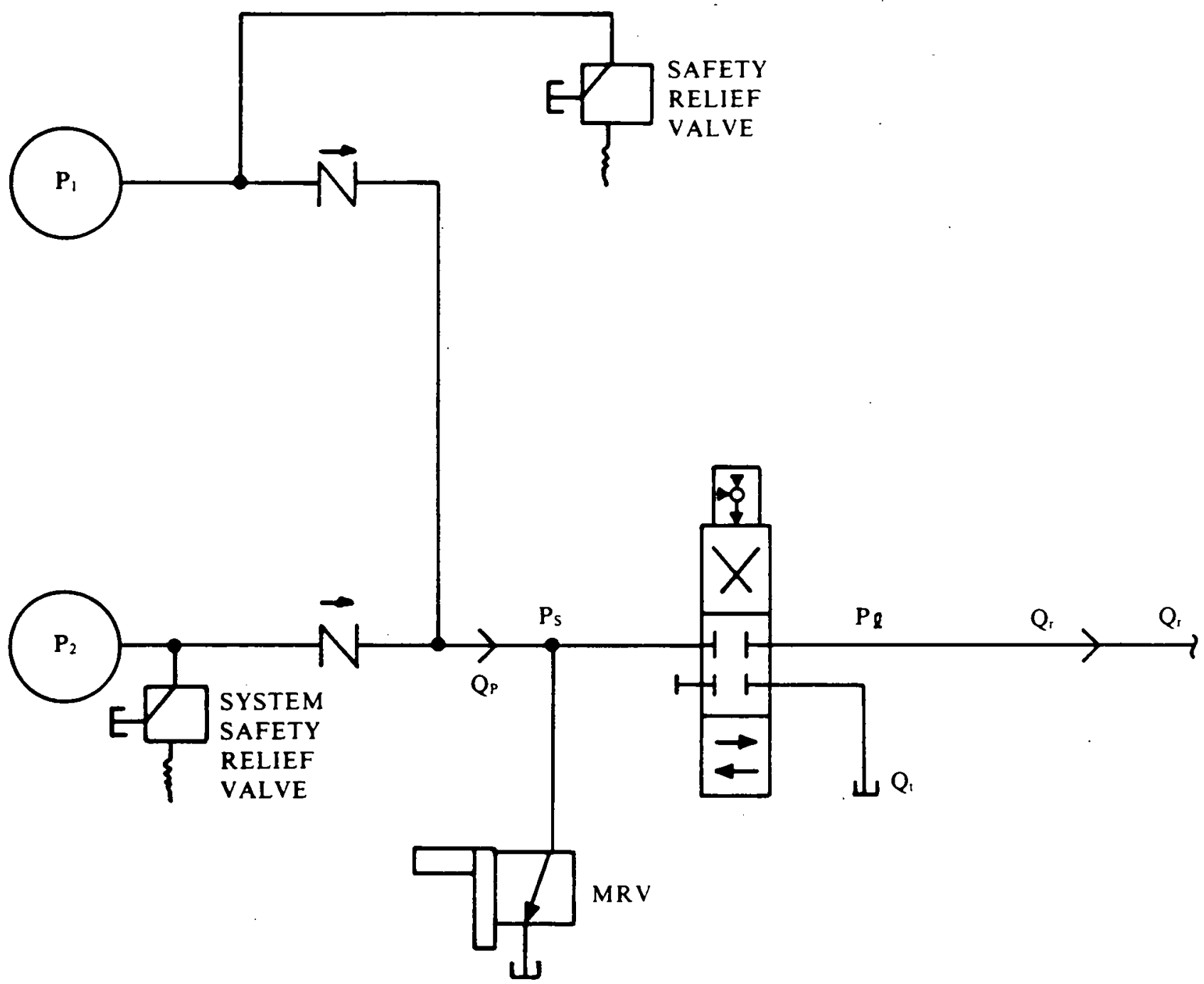

Figure 5. Closed Loop Hydraulic Speed Control Circuit With Flow Control Valve

In Figure 6 , the output of the ram velocity controller ( $i_{S}$ ) is the input to the valve position control circuit that controls the flow rate $\left(Q_{r}\right)$ going to the ram area. As the load pressure increases, the flow rate through the valve decreases, slowing the ram. The ram velocity control circuit senses the decrease in ram velocity and increases its output to compensate for the reduced flow rate caused by the load pressure increase. Load control will begin when the load pressure builds up beyond the transition pressure point. An option is being designed into the new machine logic system to allow field selection of the current line pressure switch, or to bypass that switch and start transition when the line pressure equals or exceeds a pressure value stored in the 


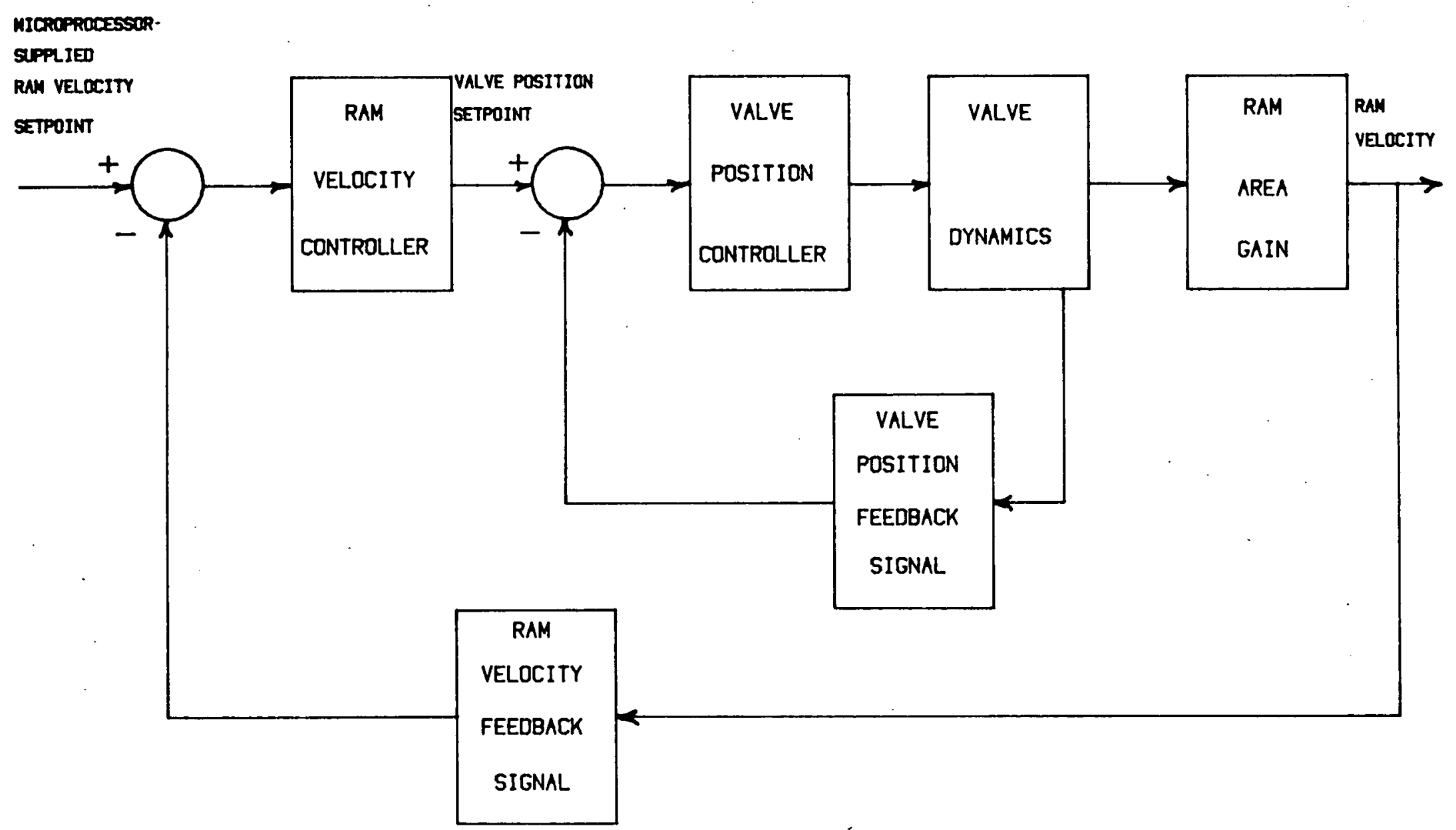

Figure 6. General Block Diagram of Ram Velocity Control 
microprocessor. Constant velocity control can then be continued up to the maximum system pressure. Caution must be used during initial development not to coin the mold from high pressures developed over small cross sections. Under load control, the force generated $\left(F_{\ell}\right)$ is proportional to both ram cross-sectional area $\left(A_{r}\right)$ and hydraulic line pressure $\left(P_{\ell}\right)$.

$F_{\ell}=A_{r} P_{\ell}$

The valve flow rate under load control must equal the losses from valve and ram leakage, plus any compressibility the fluid may undergo. The leakage losses are typically small under load control when compared to the high flow requirements in the velocity control mode; consequently, the high volume flow pump is dropped from the hydraulic circuit during load control. Solving Equation 20 for load pressure and substituting into Equation 21 results in an expression for load force in ram area $\left(A_{r}\right)$, system pressure $\left(P_{S}\right)$, leakage flow rate $\left(Q_{r}\right)$, valve constant $\left(C_{V}\right)$, and, finally, valve position signal (i).

$F_{r}=A_{r}\left[P_{s}-\left(\frac{Q_{r}}{C_{v}}\right)_{i}^{2}-2\right]$

The leakage flow rate in Equation 22 will increase typically as load pressure increases, but not always, depending on the type of seal materials used in the machine construction. Figure 7 illustrates the load pressure versus valve spool position predicted by Equation 22 for leakage flow rates of $25,50,75$, and 100 percent of maximum pump flow rate. The curve slopes in Figure 7 are extremely high; consequently, to maintain a stable closed loop response, the outer loop controller gain will have to be changed to a comparatively small valve. During load control, the ability to vary set point as a function of time is desirable. A software set point recipe will be developed to allow step or ramp changes in set point as a function of time, beginning at the velocity-topressure transition. A series of short duration step changes in set point then can be used to replace the current DEGAS mode used to manufacture some filled elastomer parts.

Figure 8 illustrates a shortened dwell pressure set point profile with DEGAS. The pressure during closing and opening is not shown in Figure 8. After DEGAS, the pressure is ramped to the cure pressure, where it is maintained until the dwell time has elapsed. At dwell termination, the pressure is ramped back to the minimum system pressure, in preparation for the stripping cycle (mold opening).

The initial phase of part stripping is important to prevent damage to the part if it sticks partially to the punch and to the 




Figure 7. Load Pressure Versus Spool Position From Equation 22

cavity, a common occurrence. The speed must be slow enough to allow the operator to separate the part without tearing it from the punch. 




Figure 8. Typical Pressure Profile With Degas

Once stripped, the ram can be opened at maximum speed until it nears the end of the cylinder, where it must be slowed, then stopped. Figure 9 illustrates the effective hydraulic circuit configuration with the new flow control valve.

The low-volume pump $\left(P_{2}\right)$ supplies hydraulic fluid to the top of the ram area during part stripping because velocity requirements are small. Solenoid $B$ becomes energized and directs that output to the top of the main ram. The main ram will not move down until sufficient pressure builds up to overcome the counterbalance valve (CBV) poppet tension. Equation 1 again relates ram velocity to pump output, except that the ram area is now the top area of the ram, which is

$$
A_{r}=\frac{\pi}{4}\left(D_{m}^{2}-D_{r}^{2}\right)
$$

The maximum stripping velocity, using the diameters in Figure 9 , is 


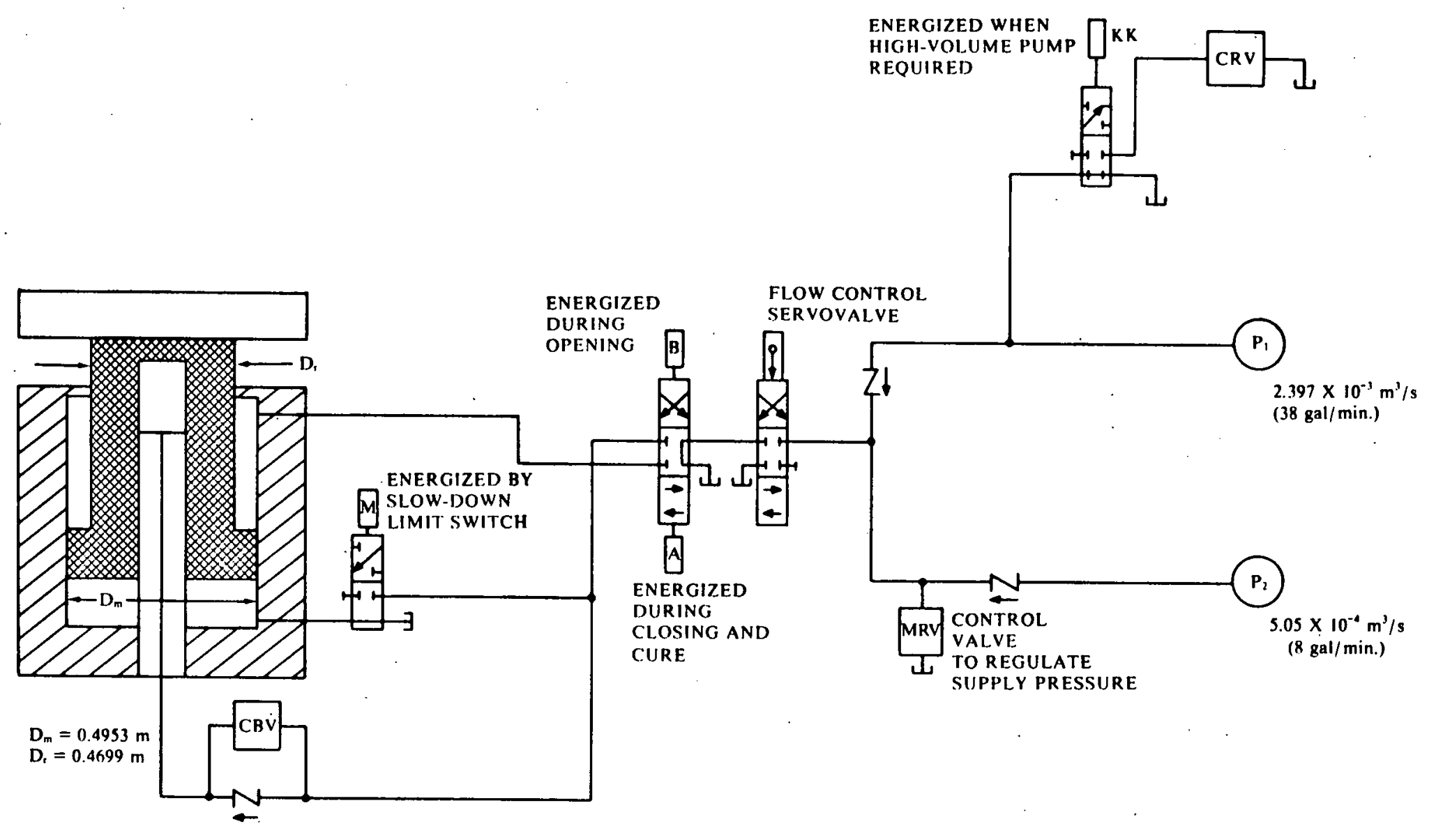

Figure 9. Hydraulic Circuit With Flow Control Servovalve 
$\mathrm{v}_{\mathrm{r}}=\frac{0.5 \times 10^{-3} \mathrm{~m}^{3} / \mathrm{s}}{0.0193 \mathrm{~m}^{2}}=0.0259 \mathrm{~m} / \mathrm{s}$

A limit switch is activated to re-energize solenoid $\mathrm{KK}$, which adds the hydraulic fluid output from the high-volume pump to the circuit and increases maximum speed by a factor of 5.75. That limit switch is set usually 76 to $152 \mathrm{~mm}$ from mold closure.

A necessary gain change or circuit change must be made at transition from load control back to velocity control, because the process gain has changed from the ram area to the inverse of the ram area. To maintain closed loop stability, the outer loop controller gain (Figure 6) must be changed to maintain a constant closed loop gain. The velocity gain also must be changed when the high volume pump is energized, because the pump flow rate increases by a factor of 5.75 .

A new constant set point regulates the controlling velocity circuit at each gain transition, having a minimum of four velocity set points: fast-close, slow-close, slow-open, and fast-open.

In summary, under closed loop control the general block diagram is like that in Figure 6. During fast closure, the total pump output goes to the booster ram area, creating a fast ram velocity. A limit switch initiates ram area transfer from booster to main and booster areas, which decreases velocity 15-fold. That velocity decrease requires either a gain change or circuit change in the outer loop controller because of the large change in process gain. The ram proceeds to closure at a new slow-close set point rate. When material resistance is encountered, the hydraulic line pressure builds up but the ram continues to close at a constant rate. Transition to load control is initiated through the microprocessor, if the normal pressure switch is bypassed, or as the pressure switch makes contact, unless bypassed. A circuit change here is almost mandatory, because a different feedback variable is necessary in addition to a controller gain change required to offset the large process gains under load control.

During load control, the set point changes as a time function to develop the desired load profile. The load force drops to minimum before mold opening. At minimum system pressure, a directional valve shifts to direct fluid at the top of the ram. The outer loop control circuitry must be shifted again at this transition point, because a different feedback variable is required in addition to a controller gain change resulting from the change in the process variable gain. Under low-volume flow, the mold opens slowly at a constant rate until a limit switch reactivates the high-volume pump. An outer loop controller gain change must take place when the high-volume pump is activated to offset the increased volume flow potential. 
Control System Architecture

Figure 10 illustrates the general block diagram of the hydraulic control system. The inner valve spool positioning control system and valve were purchased as a package. The process variable transducers were purchased separately, and the outer loop controllers were designed and built in-house.

The valve manufacturer's literature indicates that the valve control loop can be approximated by a second order underdamped model with a damping ratio $(\zeta)$ between 0.5 and 0.7 . The closed loop natural frequency $\left(\omega_{n}\right)$ is dependent upon valve selection and inner loop controller gain settings. Figure 10 can be redrawn, as illustrated in Figure 11, with the inner valve loop replaced with a second order underdamped transfer function. The subscript $j$ in Figure 11 indicates one of four possible speed segments.

Either the ram area $\left(A_{R}, j\right)$ or the maximum flow rate $\left(Q_{m}, j\right)$ changes in each speed segment to alter the process gain. Using block diagram algebra, the closed loop transfer function is this:

$\frac{C(S)}{R(S)}=\frac{D(S) G_{I L}(S) G_{p}(S)}{1+D(S) G_{I L}(S) G_{p}(S) H(S)}$

where

$\mathrm{C}(\mathrm{S})=$ speed variable,

$R(S)=$ set point,

$D(S)=$ controller transfer function,

$G_{I L}(S)=$ inner loop transfer function,

$G_{p}(S)=$ plant gain, and

$H(S)=$ feedback transducer transfer function.

Substituting the appropriate valves for $D(S), G_{I L}(S), G_{p}(S)$, and $\mathrm{H}(\mathrm{S})$ into Equation 25 after rearrangement results in

$\frac{C(S)}{R(S)}=\frac{K_{p, j} K_{I, j}{ }_{p s, j} \omega_{n}^{2}}{S\left(S^{2}+2 \zeta \omega_{n} S+\omega_{n}{ }^{2}\right)+K_{p, j} K_{I, j} K_{p s, j} K_{F B} j^{\omega_{n}^{2}}}$

where 


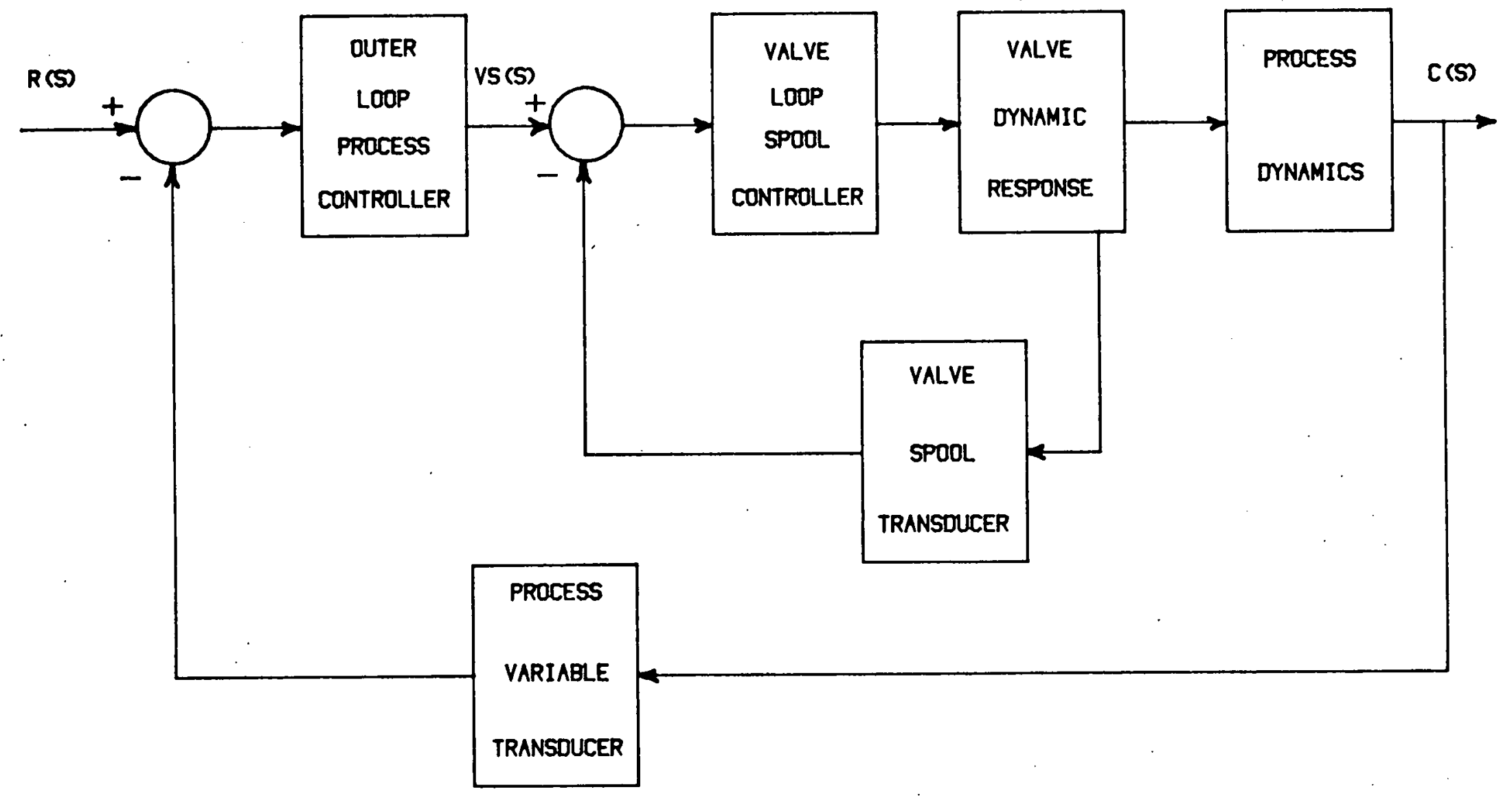

Figure 10. General Block Diagram of Press Hydraulic Control System 


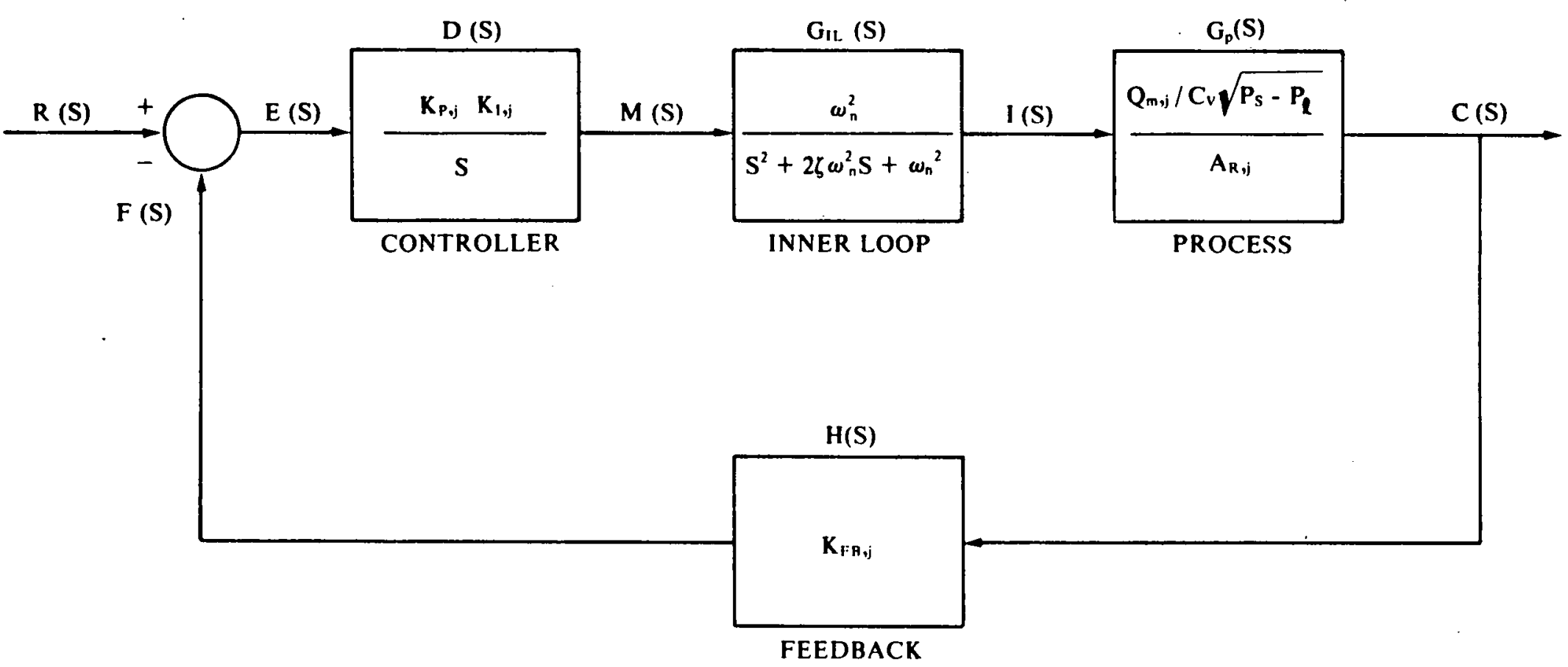

Figure 11. General Block Diagram of Hydraulic Speed Control System 


$$
K_{p s, j}=\frac{Q_{m, j}}{A_{r, j} C_{v} \sqrt{P_{s}-P_{\ell}}}
$$

To maintain a consistent closed loop response from segment to segment, the forward transfer function root locations must be the same. To maintain consistent roots, the controller constants $\left(K_{p}, j\right.$ and $K_{I}, j$ ) must change from segment to segment to match change in process gain. Since the natural frequency of the valve spool control loop is independent of the process loop to maintain constant root locations,

$K_{p, j+1} K_{I, j+1} K_{p s, j+1}=K_{p, j} K_{I, j} K_{p s, j}$

If the integration time constant is maintained constant, Equation 28 becomes

$$
\begin{aligned}
K_{p, j+1} & =K_{p, j} \frac{K_{p s, j}}{K_{p s, j+1}} \\
& =K_{p, j} \frac{Q_{m, j} / A_{r, j} C_{v} \sqrt{P_{s}-P_{\ell}}}{Q_{m, j+1} / A_{r, j+1} C_{v} \sqrt{P_{s}-P_{\ell}}}
\end{aligned}
$$

In all but the slow-close speed segment of the speed control system, the difference between supply pressure and load pressure can be considered constant. Not until resistance to closure is encountered in the slow close segment will the pressure difference change; therefore, if the pressure difference is considered constant, Equation 29 becomes

$K_{p, j+1}=\left[\frac{Q_{m, j}}{Q_{m, j+1}}\right]\left[\frac{A_{r, j+1}}{A_{r, j}}\right] K_{p, j}$

The controller proportional gain $\left(K_{p}\right)$ in ensuing segments must change as the change in ratio of either the maximum flow rates or the ram areas. During ram closing the area ratio changes; conversely, during ram opening the maximum flow rate ratio changes. The area ratio change during closing is a 15-fold increase; therefore, from Equation 30 the controller proportional gain must also increase by 15 fold. The flow rate ratio changes by a factor of 5.75 during ram opening, which requires an equal decrease in the ram controller gain.

Switching the gain or switching the entire circuit at transition are two ways to maintain-constant root locations. Three different proportional gain speed circuits are the most effective design. Two of the circuits will be used during ram closing; the other, with a gain change during opening. 
The gain change in the single opening circuit is initiated by the same limit switch that activates the high-volume pump. The switch in closing circuits is initiated from the slow-down limit switch that also effects the change in area. The two criteria for separating the closing circuits are a higher resolution feedback transducer used in the crucial slow-close segment, and nonlinearities (from increasing load pressure) in a slow-close circuit isolated from the fast-close circuit. A higher resolution feedback transducer is used during the slow-close segment to increase accuracy. Figure 12 illustrates schematically the two closing speed control circuits.

During fast-close, control relays $\mathrm{CR} 1, \mathrm{CR} 3$, and $\mathrm{CR} 4$ are deenergized while $C R 2$ is energized. Control relay $C R 2$ is energized as the operator presses the maintain contact start pushbuttons and de-energized if the operator removes one or both hands from either button. When control relay CR 2 is de-energized, the proportional mode operational amplifiers ( $O A$ ) are open, and the integrator capacitor is bled to ground, which results in a zero (nuli) set point for the valve position loop. The operator, by depressing the two start pushbuttons, provides outer loop control through operational amplifiers 1,3 , and 4 . These generate the set point for the valve position control circuit. OA 1 provides the summing junction and the proportional gain. The proportional gain is adjustable by the potentiometer $\left(\beta_{1}, R_{4}\right)$ in the OA circuit. The proportional mode output is the input to the integrator, $\mathrm{OA} 3$, whose time constant of integration is varied by its input potentiometer $\left(\beta_{3} R_{6}\right)$. The integrator output is the input to a signal inverter, which is the set point for the valve spool positioning loop.

The proportional circuits are switched by energizing control relay CR 1, which is accomplished by the slow-down limit switch. The resistances terms $R_{2}$ and $R_{5}$ have been sized to provide a 15-fold increase in the proportional gain of the two amplifiers.

Once switched, the signal from the higher resolution $102 \mathrm{~mm}$ velocity transducer is amplified by $O A 9$ and compared with a second microprocessor-generated velocity set point. The resulting signal is amplified by OA 2 , whose output is the input to the same integrator circuit. With two separate proportional circuits, some nonlinear compensation ( $\beta_{2} R_{4}$ adjustments) occurring from load pressure changes can be made without affecting the fastclose response.

The integrator circuit is common to both proportional circuits, which initially will be adjusted to influence the closed loop root locations, but once set will be common to both closing segments. 


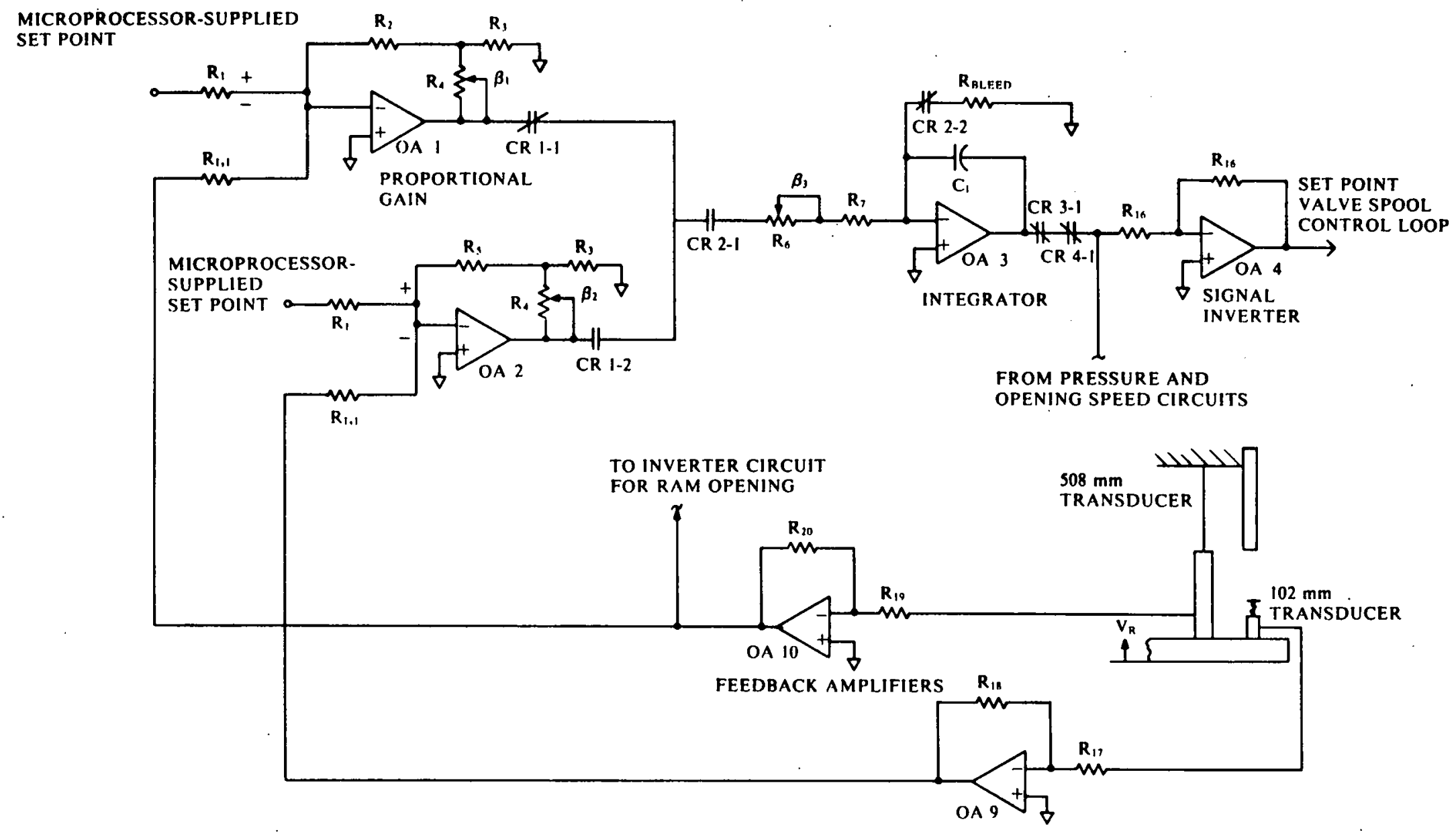

Figure 12. Closing Speed Control Circuit 
Control relay $C R 3$ is energized as line pressure reaches the pressure transition point. The closing speed circuit is isolated by the opening of contact CR 3-1. Figure 13 illustrates the pressure control circuit. The line pressure signal is amplified by $O A 12$ and is summed at $O A 4$ with a third microprocessorsupplied set point. The resulting signal is amplified by $O A 4$, whose gain is adjusted by potentiometer $B_{6} R_{4}$. A high- and low-gain switch is provided to allow a wider range of gain adjustment for the high-process gain load control loop. A second integrator, $O A 6$, is provided to allow further root manipulation by potentiometer $\beta_{7} R_{14}$ for this nonlinear segment. At the end of the pressure dwell time, the microprocessor drops the set point to the minimum pressure level.

Then, control relay $C R 5$ is energized, dropping all pressure in preparation for valve shifting to direct hydraulic fluid to the top of the main ram. The pressure circuit is deactivated as contact $C R 1$ opens. Control relay $C R 3$ is also de-energized as $\mathrm{CR} 5$ is energized. Figure 14 illustrates the ram opening circuit. Finite control of the ram opening is not required; therefore, the lower resolution feedback transducer is adequate for accuracy. $A$ signal inverter, $O A 11$, is required because of the polarity change of the transducer from closing to opening. The feedback signal again is amplified by $O A 10$ and summed with a fourth microprocessor-supplied set point at $O A 3$. The resulting signal is amplified and fed to a third integrating circuit, OA 6 . Adjustments to the root locations will be made through $\beta_{4} R_{4}$ and $\beta_{5} R_{10}$ potentiometers. Control relay $C R 4$ enables opening control, energized approximately one second after CR 5 energization. Control relay CR 6 causes the high-volume pump to enter the hydraulic circuit and produces a gain change to OA 3 by paralleling $R_{8}$ with $R_{9}$. The reduction in controller gain is offset by the increased flow gain, as predicted by Equation 30 .

Another factor is the criterion that during the slow-open segment, the hydraulic pressure must not exceed $6984 \mathrm{kPa}$ (1000 psi), which translates into an opening force of approximately $133.4 \mathrm{KN}$

(15 tons). During development, molds sometimes stick closed. The control system, to achieve the specified opening velocity, allows the pressure to build to the maximum system pressure $(13788 \mathrm{kPa})$.

Compression molds are built to absorb compressive forces. The mold inserts typically are held in place by a series of bolts around their periphery, which, when placed in tension, generally fail above the $133.4 \mathrm{KN}$ level. The product is a mold that tears itself in half, if the system pressure is allowed to go to maximum level, as it would if the mold halves were stuck shut.

To prevent that occurrence, an added pressure switch set for $6900 \mathrm{kPa}$ will energize an over-pressure relay. That relay will 


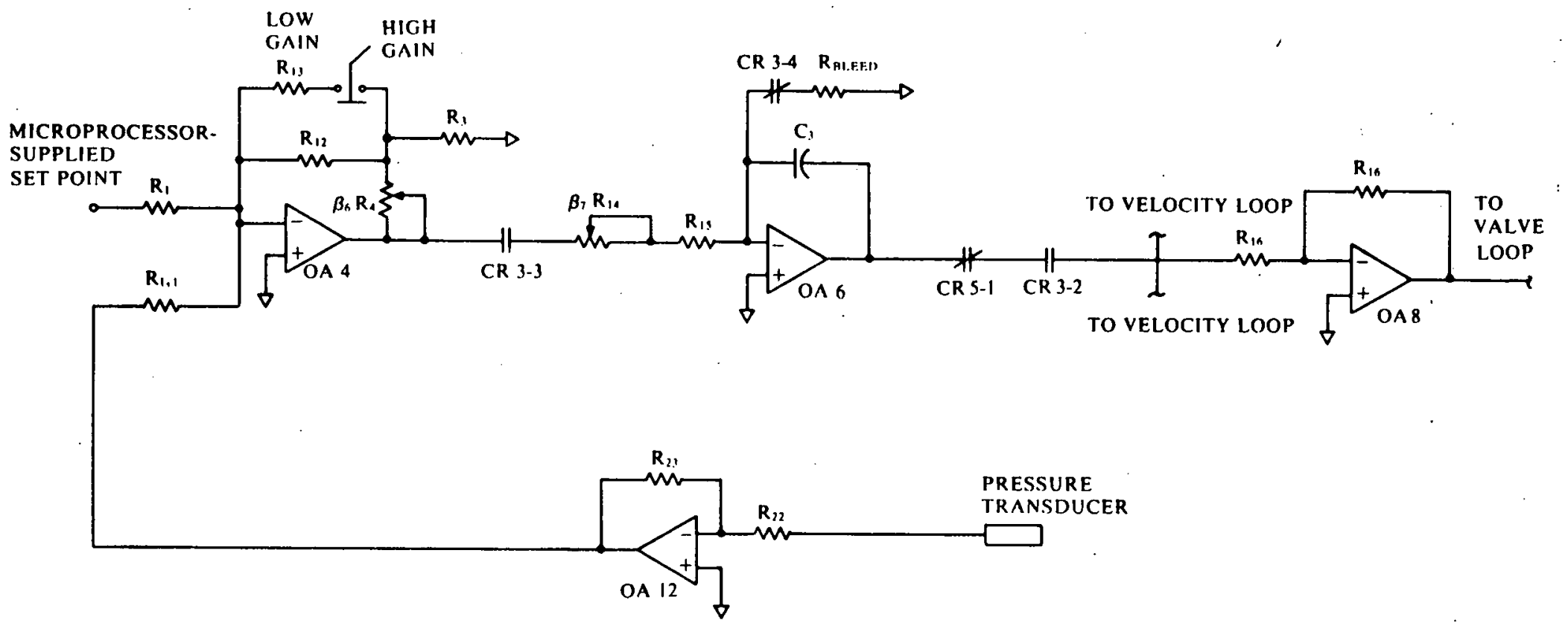

Figure 13. Pressure Control Circult 




Figure 14. Opening Speed Control Circuit 
cause the press to idle at no pressure, and will lock it there until an operator unlocks it by depressing a reset pushbutton. Manual attempts then may open the stuck ram. The closed loop control system will be deactivated automatically for over-pressure or emergency conditions.

Ten additional control relays will be added to the machine logic system to achieve the desired machine response under closed loop control.

In summary, four outer loop analog control circuits were designed to accept process set points from the microprocessor and compute the set point for the inner valve loop. The circuits are switched from the same devices that initiate ram area changes, hydraulic flow rate changes, and velocity-to-pressure transition. The gain changes are commensurate with the requirements of Equations 22 and 30 . The flow control valve and valve spool position controller were purchased as a unit. The hydraulic circuit has been altered to accommodate the new directional valve, flow control valve, check valve, and fluid filter. A microprocessor development system and microprocessor have been procured to generate set points, and read process information and output logic commands to the machine logic system. The remaining unanswered question is what the controller gain values should be in the flow and pressure circuits to produce the desired closed loop response.

\section{Speed Control Simulation}

A written digital simulation computer program (Appendix B) allows investigation of the gains and architecture for the velocity control mode. Three configurations were investigated: no integral mode, first order lag, and proportional-integral.

Proportional-integral was the only architecture that produced stable responses. The simulation block diagram for the proportional integral architecture is presented in Figure 15 . The $Y_{i}$ values in Figure 15 are stated variables requiring numerical integration, and the $X_{i}$ values are intermediate calculations. Table 2 lists selected values of $\mathrm{K}_{\mathrm{Al}}$ and $\mathrm{K}_{\mathrm{A} 2}$ as a function of the potentiometer percentage illustrated in Figure 12.

The integration time constant $(\tau)$ is the only variable in the simulation. The valve gain $\mathrm{K}_{\mathrm{V}}$ in Figure 15 is assumed constant for all closing speeds, even though Equation 20 indicates that as the line pressure increases, the flow rate decreases. The line pressure will increase only more than a small percentage of the total ram stroke. The natural frequency $\left(\omega_{n}\right)$ and damping ratio $(\zeta)$ were obtained graphically from the valve manufacturer's literature. The feedback amplifier gain (KFB) boosts the feedback transducer signal to achieve a range of 0 to $10 \mathrm{~V}$. The ram 


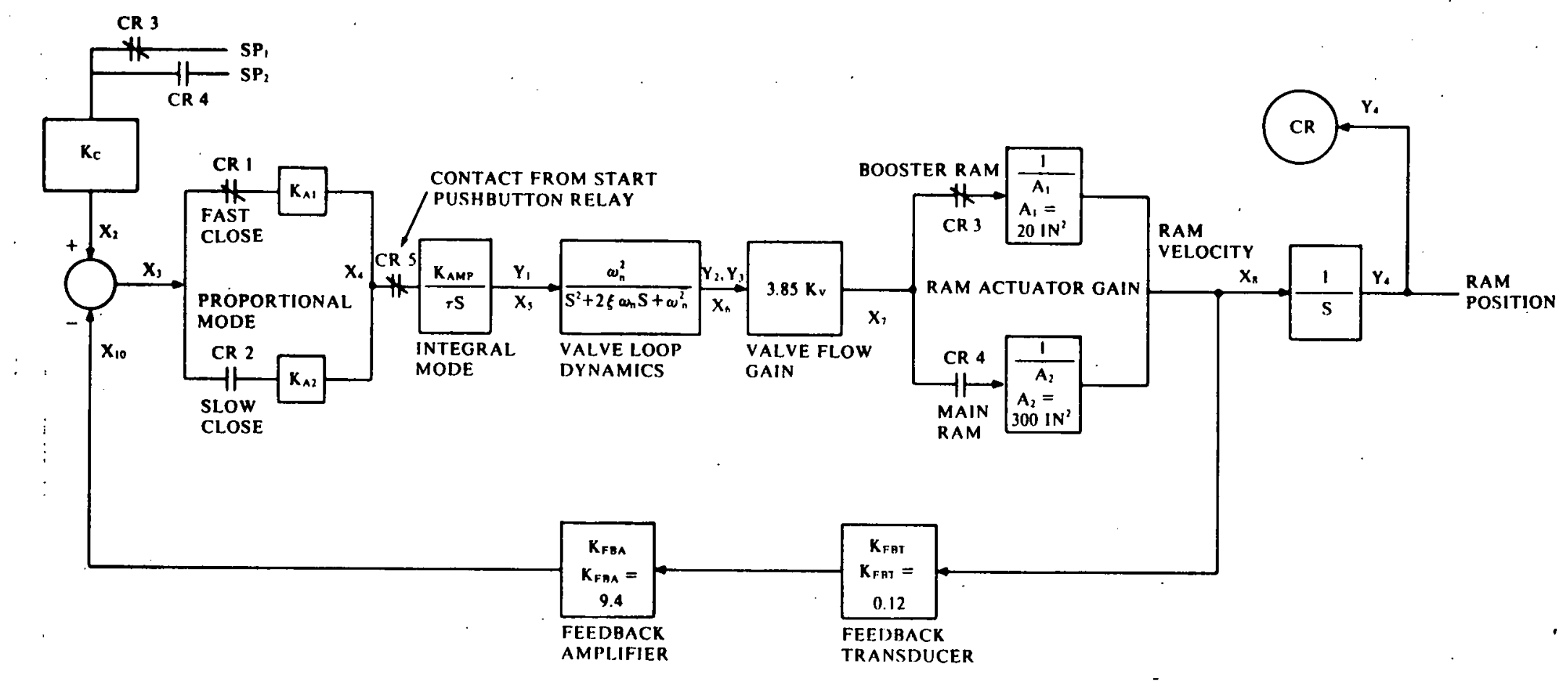

Figure 15. Hydraulic Velocity Control for Press Design Option 5, Integral Mode Added 
Table 2. Proportional Gain for Various Potentiometers

\begin{tabular}{|c|c|c|}
\hline $\begin{array}{l}\text { Potentiometer } \\
\text { Percent }\end{array}$ & $\mathrm{K}_{\mathrm{A} 1}$ & $\mathrm{~K}_{\mathrm{A} 2}$ \\
\hline $\begin{array}{r}0 \\
20 \\
40 \\
60 \\
80 \\
100\end{array}$ & $\begin{array}{l}0.024 \\
0.7 \\
1.38 \\
2.05 \\
2.73 \\
3.40\end{array}$ & $\begin{array}{c}0.50 \\
10.7 \\
20.9 \\
31.1 \\
41.3 \\
51.5\end{array}$ \\
\hline
\end{tabular}

actuator areas are machine parameters that are constants. Gain $\mathrm{K}_{\mathrm{C}}$ is the set point conversion gain to convert engineering units to voltage.

The integral of the squared error (ISE) and the integral of the absolute error (IAE) were used as performance indices.

$I S E=\int_{0}^{t} x_{3}^{2} d t$

$I A E=\int_{0}^{t}\left|x_{3}\right| d t$

Simulations were conducted over a range of gain and time constant values. Selected simulations are illustrated in Appendix A. Small proportional gains produce overdamped results that become more underdamped, as their magnitudes are increased, eventually to become totaliy underdamped, as indicated in simulations 1 through 6 . Small time constants of integration produce the opposite effects. By increasing its magnitude, the closed loop response tends to dampen (simulations 7 through 9).

The results of the simulation dictated the controller configuration and the gain magnitudes for the initial hardware design.

\section{ACCOMPLISHMENTS}

The early goals of this project were to design, procure, and install the hardware required to achieve closed loop ram speed and load pressure control. The first two goals have been completed. 


\section{FUTURE WORK}

The next stage of the project is to install the remaining hardware, start software development, implement hardware and software, and test the resulting system. 
Appendix A

RAM VELOCITY VERSUS TIME SIMULATIONS 




SIMULATION 1

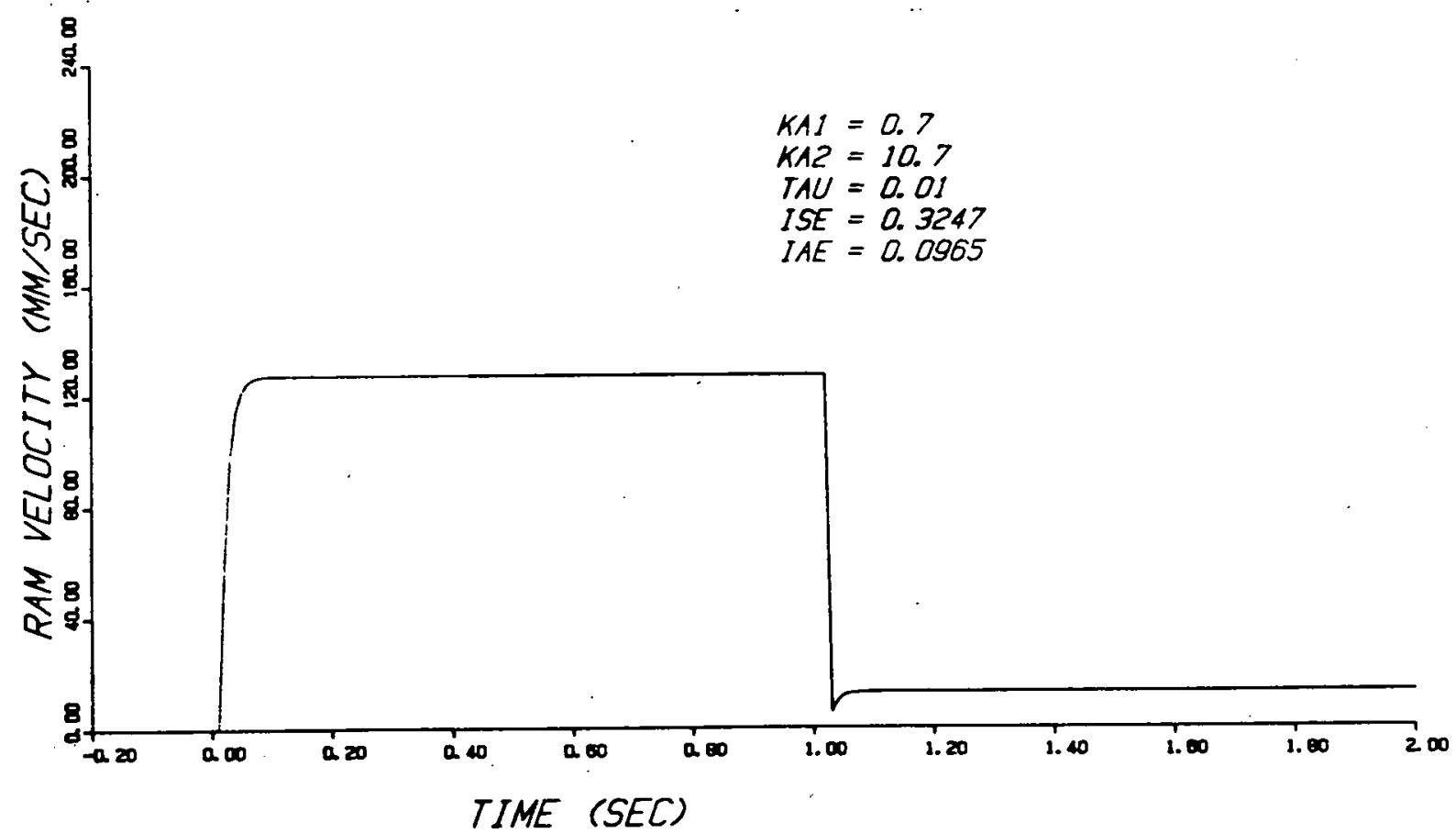

SIMULATION 2 


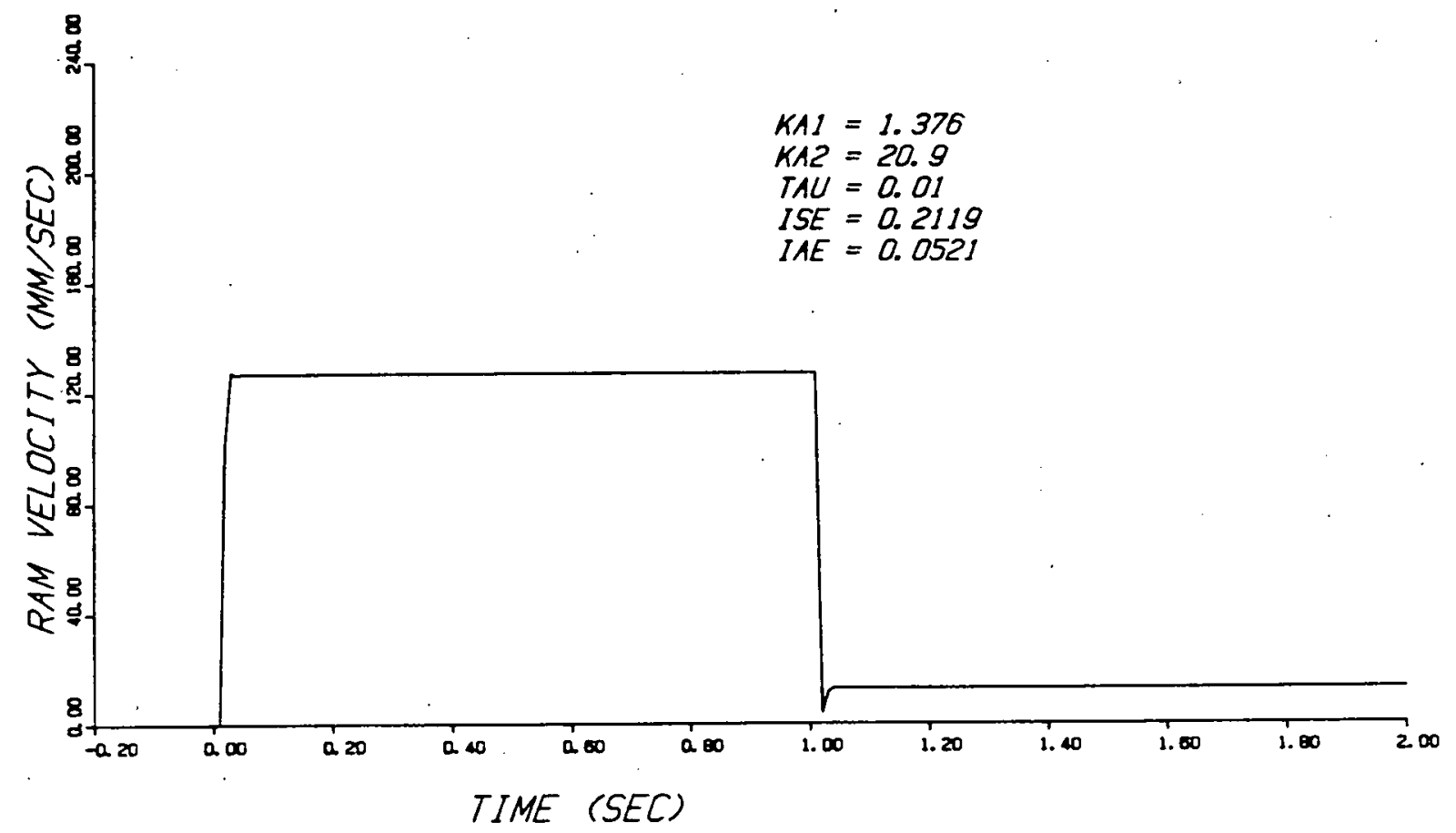

SIMULATION 3

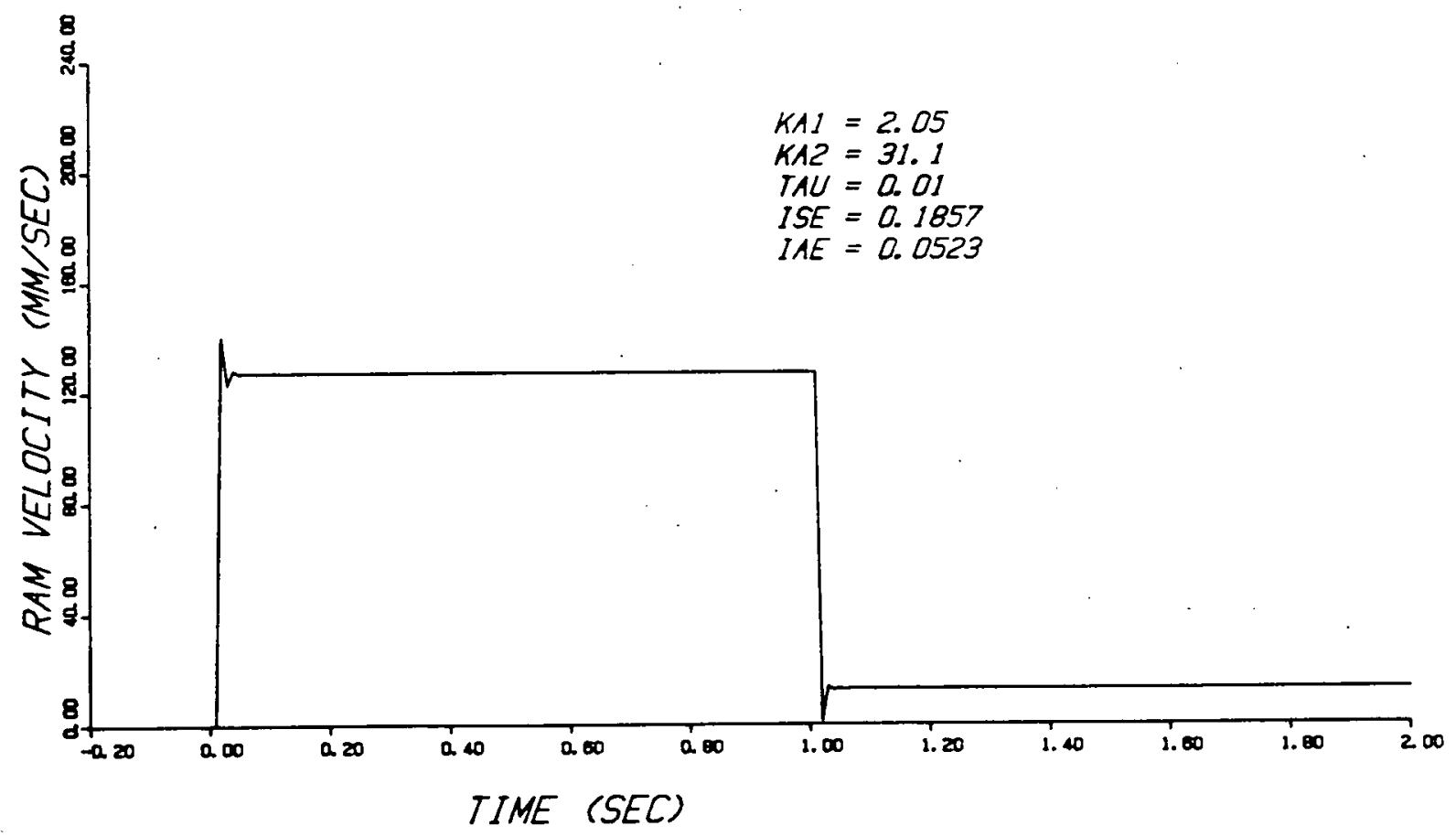

SIMULATION 4 




SIMULATION 5

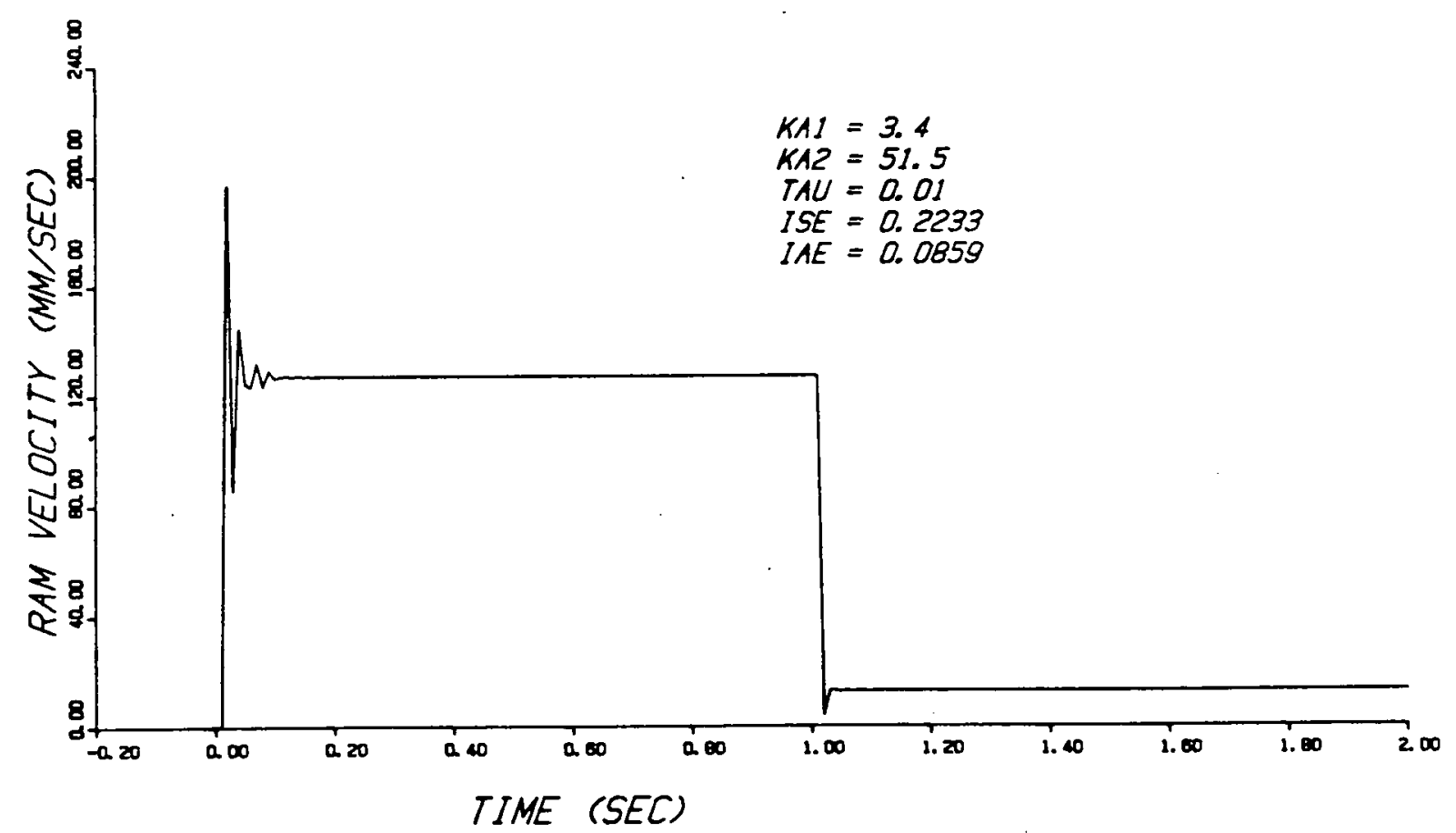

SIMULATION 6 

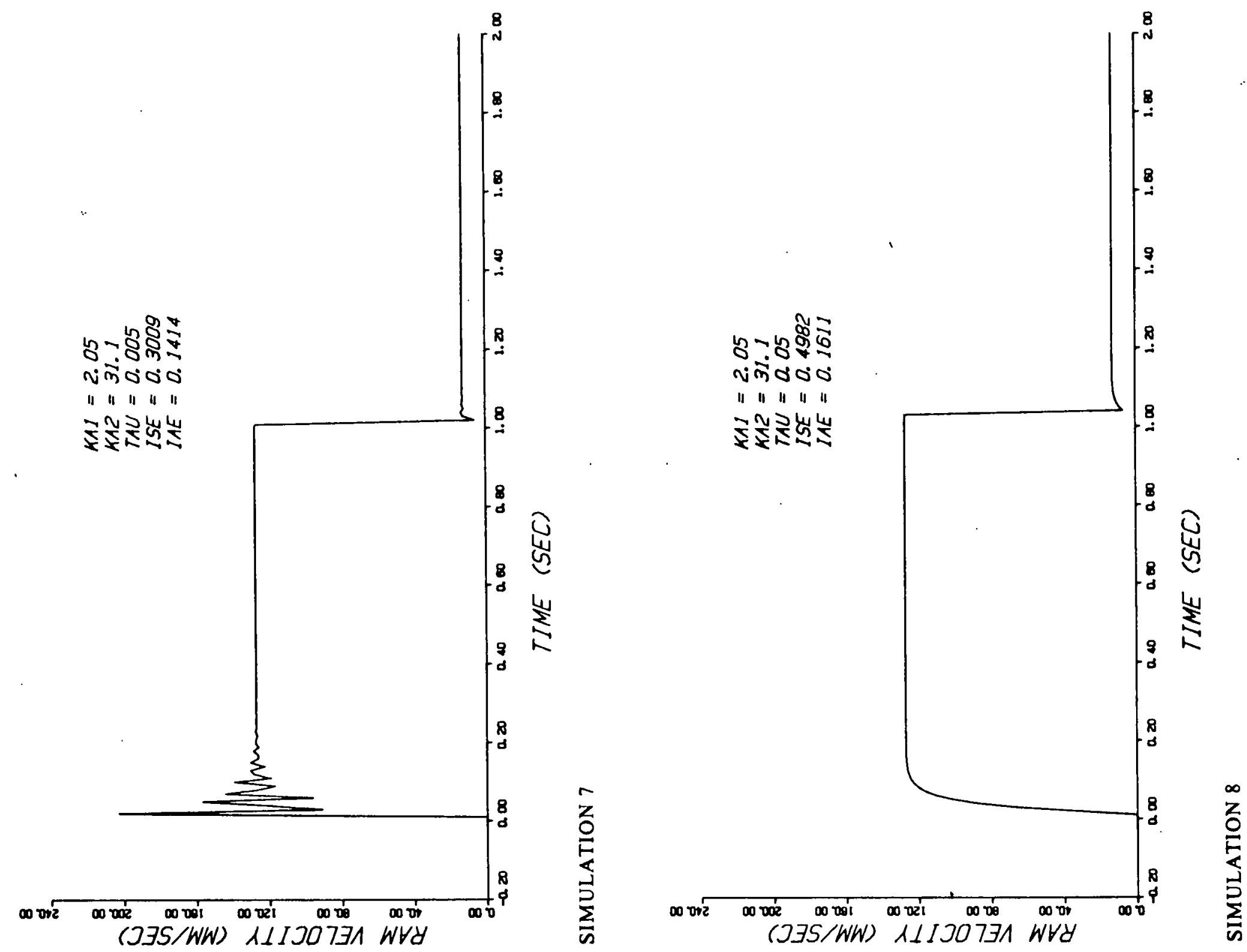

京 




SIMULATION 9 


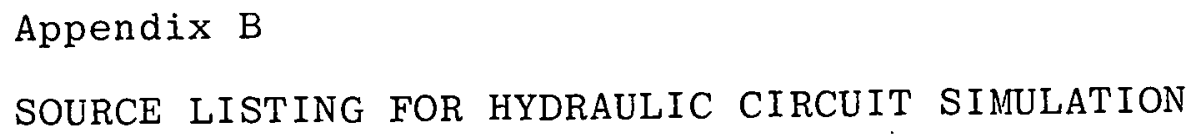


PAGE NC. ]

OVERLA.Y (HYDCI, $r, r)$

PRCCRAM CCNTRL (INPUT, CUTPUT, TAPE]=INPUT, TAPE 2=OUTPUT, TAPE 5)

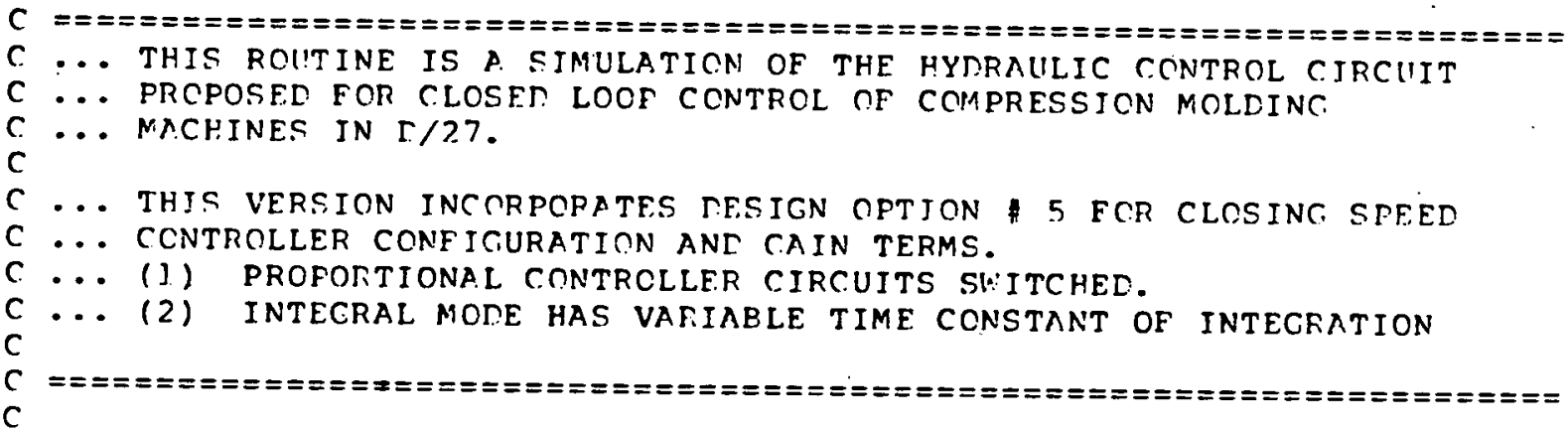

COMMON/AA/X (5C), $P(40), Y(22), Y T(2), F(10), C(9), N Y, N X, N P, M M S P$ COMMCN/EE/XSTF $(1,50), X T(\Omega), X T H(9), I H(\Omega), N H, I M A X, H(9)$

CCMMCN/CC/FAMP (1 4 ), STPT (1 4), TIM ( 4 ), DWELL (14), JFLAC, NSEG, SP, SP]

CCMMNN/DD/I TY, ITX, ICY, IGX, NC, SB (J 2), PL, PR, IRUN, I PAGE, IX, IY, NOUT

CCMMON/EE/XG $(8,2), Y G(8,2), M S S, N G Y(8), N C X(8), N T Y(8), N T X(8)$

CCMMICN/FF/IADJ, MX,MY,JX (8),JY (8), XS (9C], 8), YS (9C1,8)

CCMMCN/GG/ND (2C), NPT, NSP, NTM, PTIME, ISW

CCMMCN/HH/PTIME, ETIME, DELT,JTI (10), IT2(IC),MT (3),MN(3),JD (3), MS (3)

C

COMMCN/II/ISAMP, NTIME, NDY, INY, CII (2C), CDO

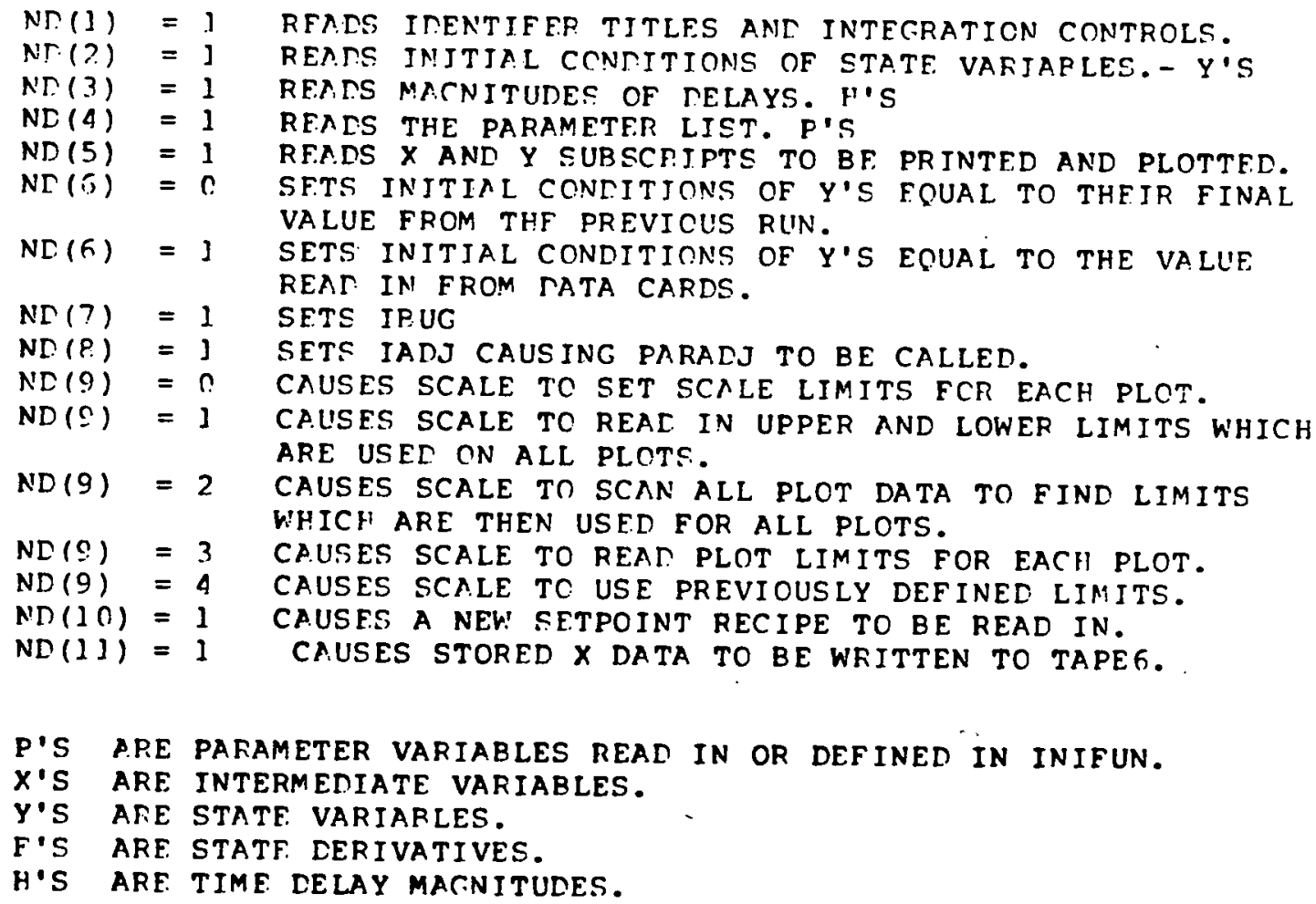


PAGE NO. 2

C
C
C
C
C

X(1) AND Y(NSYS+1) ARE RESERVED FCR TIME.

BTIME = BECINNING TIME

ETIME $=$ END TIME.

PTIME = PRINT OUT INTERVAL

DELT = INTECRATION STEF SIZE MUST BF .1,.2, .5 OR A MULTIPLE OF 10 TIMES THOSF STEP SIZF VALUES.

10] FORMAT(IHJ, JOX, AGHTHE OUTPUT INTERVAL IS TOO SMYLL - OUTPUT AFKA, - 31 HY EXCEENS J OOI PTIMF RESET TO, F?. C//1

102 FORMAT (//, ICX, 23HTHE ISF OF THE LDOP IS, JPE] $/ .7 /] \mathrm{CX}$,

*2.3HTHE IAE OF THE LOOP IS, JPEjA.?)

$1 \cap ?$ FORMAT $(20,(] X, I]))$

104 FORMAT $(4(5 X, 2 H Y(, I 2,4 H)=, F] 2,5,2 X))$

105 FORMAT $(4(5 X, 2 \mathrm{H} X(, \mathrm{~J} 2,1 \mathrm{H})=, \mathrm{F}) 2.5,2 \mathrm{X}))$

J. 50 FORMAT ( 8 (FO. 4, JH) )

16C FORMAT $(8(I 2,1 X))$

161 FORMAT(I $2, J X, I 2, J X, I 3)$

162 FORMAT(2X, 3RHHYDRAULIC SPEET CONTPCL 3Cr TCN HRM.)

c

163 FORMAT $(5(F) 2.6,2 X))$

C

IRUN $=0$

1 I PACE $=0$

$I R U N=I R U N+I$

$\operatorname{READ}(1,103)(N D(I), I=1,2 C)$

IF (EOF (1)) 999,2

2 IBUG $=$ ND(7)

JSTOP $=0$

NSUM $=0$

DO $3 I=1,20$

3 NSUM $=$ NSUM + ND(I)

IF (NSUM.ES. O) JSTOP $=1$

IF (JSTOP.Eח.I.AND. IARJ.ES.C) GO TC פog

$\mathrm{IADJ}=\mathrm{ND}(8)$

C

c

C

ABOVE READS IN NDATA AND TERMINATES PUN IF NO CHANGES IN NR

CALL INPUT

CALL INIFUN

IF (NX.EO.O) GO TO 4

CALL INTCAL

4 CALL DIFFEQ

C

CALL ALIST

C

ABOVE INITIALIZES PROGRAM ANI RRINTS CUT HEADER INFO.

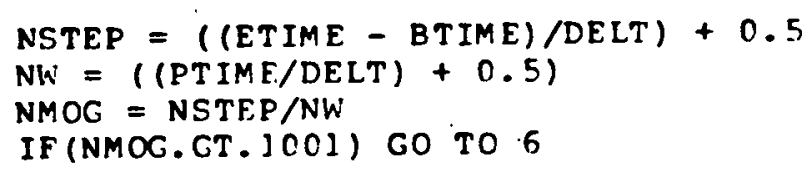







PACE NO.

C

C NOW THAT ITERATIONS COMPLETE PRINT ANE PLCT RESULTS.

C

IF (ND(11).NE. 1) GO TO 201

V:RITE $(6,162)$

V'RITE $(6,161) M X, N P, J I$

WRITE $(5,16 C)(J X(I), I=1, M X)$

WRITE $(6,163)$ (P (I), I=1, NP)

DO $200 \quad I=1, J I$

200 W'RITE $(6, J 50)$ (XS (I,JJK), JJK $=1, M X)$

ENDF ILE 6

201 CONTINUE

NOUT $=\mathrm{JI}$

IF(ITY.EO.0) GO TC 16

C PRINT Y TARLES.

C

CALL PRTTBL(JI, O)

16 IF(ITX.EQ. ก) GC TO J?

C

PRINT $\times$ TABLES.

CALL FRTTRL (JI, I)

17 IF (IGY. EQ.R) GC TO IR

c

C

PLOT Y DATA.

$N G=I G Y$

CALL PLOT (YS, $1, Y C$ )

IPAGE = IPACE + 1

18 IF (ICX.EQ. N) CO TO 10

C.

C PLOT $\times$ DATA.

C

NC: $=I C X$

CALL PLCT (XS, $0, X C)$

IPAGE = IPAGE + I

C

C

C.

19 IF(IADJ.NE. $n$ ) CALL PARADJ

WRITE $(2, J C 2) Y(5), Y(5)$

IF (JSTOP.NE. O) GO TO SQ?

GO TOJ

999 STCP

END

SUBROUTINE INPUT

C

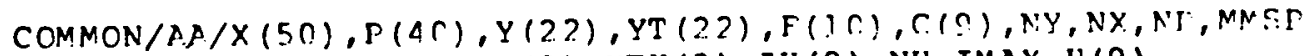
COMMON/BB/XSTR $(1,5 C), X T(\Omega), X T Y(O)$, JH (S),NH, IMAX, F( $(\Omega)$ COMMON/CC/RAMP(1A), STPT (1A),TIM (14), NUELL (1A), JFLAC,NSFC, SP, SPI CCMMON/DD/ITY, ITX, ICY, ICX, NC, SE (J 2$), F L, F R$, IPIIN, I FACE, IY, IY, NOIT COMMCN/E.E/XG $(q, 2), Y C(f, 2), M S S, N C Y(P), N G Y(P), N T Y(P), N T Y(\varepsilon)$

COMMON/FE/IALJ,MX, MY,JX $(8), J Y(P), Y \subseteq(Q 0,1, P), Y \subseteq(901,8)$ 
PACE NO. 5

COMMCN/GC/NR(2R), NPT, NSF, NTM, PT IMF, ISW

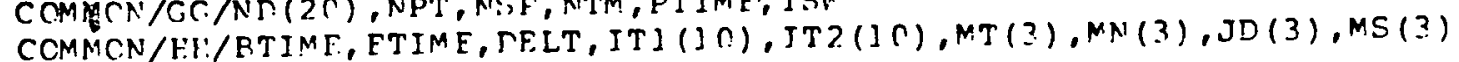

$c$

JR.C FCRMAT (RF] O. R)

In] FCRMAT (] RAP)

JC? FCRMAT $(A(I 2, J X))$

I C. FOPNAT $(\Omega(] X, I ?))$

c.

lOE FCRMTT $(?(3 A P, J X))$

C.

C

7.ERC OUT ARRAYS

ro ? $I=1,8$

nC $\mathrm{J} J=1$, ?

$X C \cdot(I, I)=n . r$

J $Y C(I, J)=0 . r$.

IF (NS. (5) . FO. C) GC TC?

DC $2 \quad I=1, ?$

NCY (I) $=C$

NCX. (I) $=$ ?

$\operatorname{NTY}(I)=0$

$\operatorname{NTX}(I)=n$

$J Y(I)=0$

$2 J Y(I)=C$

I T $Y=I T X=I C Y=I \& X=M Y=M X=0$

3 IF (NDII).ES.C) C.O TO

c.

$c$

c.

c.

c

C.

RFAF IN TU!O $8 C$ CHARACTER TITLFS, MCLD TITLE(MT), MCLT NUMBER (MN), RFAL IN TH: ANDL SECTION(MS). THEN REAT DATE (JD), NUMEER OF Y'S, X'S, P'S, ANT H'S AS W'FLL AC BECIN ANE ENI TIMES, INTEGRATION SIZE, AND PRINT INTERVA.L.

$\operatorname{RFAN(1,10])(ITJ(I),I=1,10)}$

$\operatorname{REAN}(1, j \mathrm{O})(\operatorname{IT} 2(\mathrm{~J}), \mathrm{J}=1, \mathrm{~J})$

RE.AD $(1, J C .5)(J \cap(K), K=1, ?)$

REAT: $(1,3 r ?) N Y, N X, N P, N H$

REAT (1, J RC) PTIME, FTIME, DELT, FTIME

$Y(N Y+1)=$ ETIMF

$Y(N Y+2)=D E L T$

$N Z=N Y+2$

NMAX $=2 * N Y+2$

4 IF (ND (2). EN.R) GO TO 5

$\operatorname{READ}(1, J \cap \cap)(Y(I), I=1, N Y)$

GC TC 7

5 IF (NI (G) . NE.C.) GO TC ?

DO $6 \quad I=1, N 2$

$6 Y(I)=Y T(I)$

7 DO \& I $=1, N 2$

C

$8 \mathrm{YT}(\mathrm{I})=\mathrm{Y}(\mathrm{I})$

C

INTEGRATION CONTROLS REAN IF ND(1) = 1 ABOVE. ALSO, THE INITIAL CONDITICNS OF THE STATF VARIABLES ARE SET.

IF (ND(3).ES. R) GO TO ? 


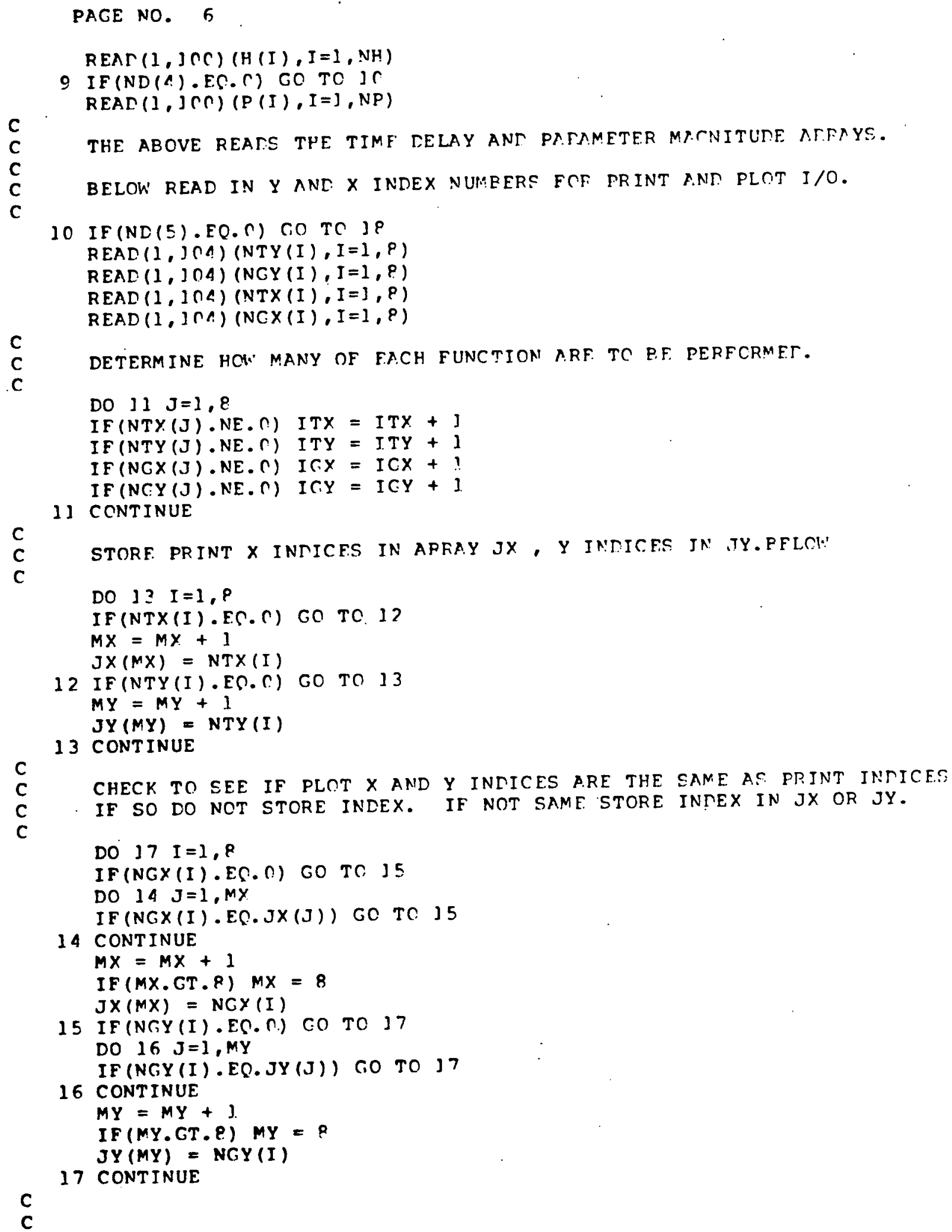

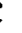

c

C DETERMINE HOW MANY OF FACH FUNCTION ARF. TC P.F. PERFCRMET. 
FACE NC. 7

c.

C

38. IF (NI. (1O). NE. O) CALL RECIPE

RETURN

END

C SUBRCUTINE RECIPE

C

r.

C FEACS IN THE MAJOR LOCF SET PCINT RECIPE.



C

] FCRMAT (2F]R. C)

2. F CRMAT (I 2)

C

REAT $(1,2)$ NSEG

TO ? I $=1, N S E C$

C.

? REAT $(1, j) \operatorname{RAMP}(I), \operatorname{STPT}(I), \operatorname{TIM}(\mathrm{I})$

$J F L \cap C=C$

RETURN

END

SUBRCUTINE A.LIST

$\mathrm{C}$
$\mathrm{C}$
$\mathrm{C}$

HEANER OUTPUT ROUTINE.

COMMCN/A.A X (50),P(10),Y(22), YT (22), F(1C),C(O),NY,NX,NP,MMSP COMMON/RP/XSTR $(1,50), X T(0), X T H(0), I H(0), N H, \operatorname{IMAX}, H(9)$

CCMMCN/CC/RAMF (14), STPT (1A),TIM (14), NVELL (14), JF LAC, NSEG, SF, SPI COMMCN/ח /ITY, ITX, IGY, IGX,NG, SR (12), PL, PR, IRUN, I PAGE, IX, IY, NOUT COMMCN/GG/NL (2C), NPT, NSP, NTM, PT IME, ISW:

CCMMCN/IH/ETIME, ETIMF, CELT, ITI (10), IT2(10),MT(3),MN(3),JD(3),MS(3)

C.

C

C

JOR FORMAT(1H), $\mathrm{X}, 4$ THFYYRRAULJC SPEET CONTROL ?OO TON HFM RAM CLOSING,

$1131 * *$ RUN DATF, 3A.8, 2X, PHRUN NO. I $2,2 X$, OHPACE NO. , I $3 /)$

] $C$ I FCRMIT $(1 X, 3>C(1 H *) /)$

] 2 FCRMAT (65X, ] CHIESCRIPTCR/)

103 FCRMAT $(2 \cap X, 1$ I A $/ 2 \cap X, 1$ INA $/ /)$

1CL FCRNAT $(5 X$, J SH* PROCRAM CONTRCLS, $24 X, J H *)$

J 5 FORMAT $\left(5 X, 1 H^{*}, 12 \mathrm{X}, \mathrm{JH}^{*}\right)$



] $\cap 7$ FORM T $\left(/ / 5 X, \triangle \Delta\left(1 H^{*}\right)\right)$

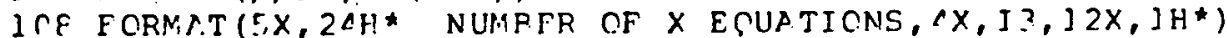

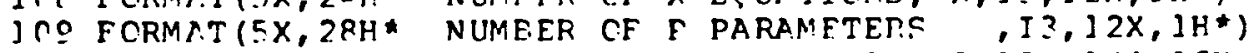

1 ] C FCRMAT $(5 X, 2) H *$ NUMEER CF H CELAYS, 7X, I?, 12X, JH*, ]6X, 1H*,2X,

* I SHSIMULATION NATF, $8 X, ? A R, 2 Y, J H *)$

111 FCRMAT $\left(5 x, 121{ }^{*}\right.$ START TIME, JกX,FP. $, 3 x, 10 H S E C C N D S$ *)

112. FCRMAT $(5 X, 11 H *$ ENT TIME, $11 X, F$. $4,3 X, 3$ CHSECONDS *)

1]? FORMAT ( $\mathrm{X}$, J FH* OUTPUT INTERVAL, 6X,F7.4,3X, J OHSECCNIS *)

1]4 FCRMAT (5X,25H* INTFGRATCR STEP SIZF, FE. $1,1 X, 1$ CHSECCNIS */5X, $\left.+44\left(1 H^{*}\right) / / 1\right)$

115 FORNAT $(/ / 5 X, \wedge \triangle H T H E$ FCLLOV:INC ARE THE TIMF DELAYS IN SECCNDS/)

l] 6 FCRMAT $(\Delta(5 X, 2 H H(, I 2,4 H)=, F J 2.2,2 X))$ 
PAGE NO. 8

117 FORMAT (//5X, ?PHTHE FCLLOWINC: IS THE FARAMFTER LISTINC/)

118 FORMAT $(4(5 X, 2 H P(, J 2,4 H)=, F] 2.6,2 X))$

110 FCRMAT $(/ / 5 X, 48 H E N S U I N C$ ARE. THE INITIAL CCNITITIONS CF THF. STATE, - 9hVARIABLES/)

120 FORMAT $(\Delta(5 X, 2 H Y(, J 2, \Delta H)=, F] 2.5,2 X))$

121 FCRMAT $/ / 5 X, \triangle 9 H E N S U I N G$ ARF. TPE $X$ VALLIFS AFTER INIFUN ANE INTCAL, *? ?HBUT BEFORE THE FIRST INTEGRATION./)

122 FCRMAT $(A,(5 X, 2 H X(, I 2,4 H)=, F] 2 . C, 2 X))$

123 FORMAT $\left(40 X, 51\left(1 H^{*}\right)\right)$

124 FORMAT $140 \mathrm{X}, 39 \mathrm{H} * *$ FAST CLOSE GA.IN, $6 \mathrm{X}, 2 \mathrm{H}=, \mathrm{FO} .4,15 \mathrm{H}$ VOLTS/VOLT ** $+1 C X, 19 H * *$ SLON CLOSE CAIN, $K X, 2 \mathrm{H}=, F O .4, J 5 \mathrm{H}$ VOLTS/VOLT $* \star * / 4 \Gamma X$,

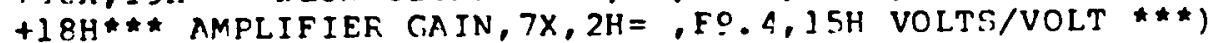

125 FORMAT $(40 \mathrm{X}, 2 \mathrm{H} * *$ AMP TIME CONSTANT, $4 \mathrm{X}, 2 \mathrm{H}=$, F9.8, PH SECCNDS, $4 \mathrm{X}$,


$+3 \mathrm{H} * \star / 4 \mathrm{CX}, 25 \mathrm{H} * *$ SPOCL NAMPING FACT, $2 \mathrm{H}=, \mathrm{F} \cong .5,32 \mathrm{X}, 3 \mathrm{H} * * *)$

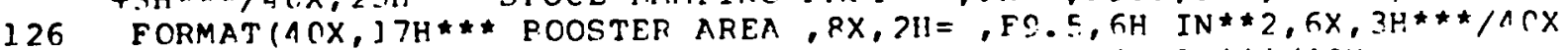
,$+ 18 \mathrm{H} * *$ MAIN RAM AREA $, 7 \mathrm{X}, 2 \mathrm{H}=, \mathrm{F} 0.5,6 \mathrm{H} I \mathrm{IN} * 2,6 \mathrm{X}, 3 \mathrm{H} * * / 1 \mathrm{CX}$, $+27 H * *$ FEEPPACK AMP. CAIN $=$, FO. $5,15 \mathrm{H}$ VOLTS/VOLT ***)

127 FORMAT $\left(40 X, 31 H^{*}\right.$ * TRANSITION FAST TO SLOV AT ,FG. ?,7H INCPES, $2 X$, $+3 H \star \star \star)$

131 FORMAT $(3 \varrho X, 1 H *, 12 X, 15 H S E T$ POINT RECJFE, $32 X, 1 H *)$

132 FORMAT $\left(30 \times, 42\left(11 !^{*}\right)\right)$

133 FORMAT 30 OX, $42 \mathrm{H}$ * RAMP * SETPOINT * DWELL * SFCMFNT *

134 FORMAT $\left(39 X_{4} 42 \mathrm{H} *\right.$ PSI/S * PSI * SEC * NO. *)

135 FORMAT $\left(39 \mathrm{X}, \mathrm{jH} *, \mathrm{~F} F, 2,2 \mathrm{H} *, 2 \mathrm{X}, \mathrm{F} \kappa, 2,2 \mathrm{X}, 3 \mathrm{H}^{*}, \mathrm{~F} 5.2,2 \mathrm{H} *, 4 \mathrm{X}, \mathrm{I} 2,5 \mathrm{X}\right.$,

* $\left.1 H^{*}\right)$

136 FORMAT $(/ / /)$

C

$I P A C E=I P A C E+]$

WRITE (2, 10O) (JN(I), I =1, ?), IRUN, I PAC.E

WRITE $(2,101)$

W'RITE $(2,102)$

WRITE $(2,1(3)(\operatorname{IT})(I), I=1,10),(\operatorname{IT} 2(J), I=1,10)$

WRITE $(2,101)$

WPITE $(2,107)$

WRITE $(2,10.4)$

WRITE $(2,3) .5)$

WRITE $(2,306) N Y$

WRITE $(2,108) \mathrm{NX}$

WRITE $(2,10 Q) N P$

H'RITE $(2, J] 0) N H,(J D(J), J=1,3)$

U'RITE $(2,111)$ BTIME

WRITE $(2,112)$ ETIME

W'RITE $(2,1]$ ?) PTIME.

WRITE $(2,1] \triangle)$ DELT

WRITE $(2,1 \cap 1)$

IF (NH.EO.S) GO TC I

WRITE $(2,115)$

WRITE $(2,101)$

WRITE $(2,1] 6)(I, H(I), J=1, N H)$

URITE $(2,10.1)$

1. IF (NP.E.C.C) GO TO 2

WRITE $(2,117)$

WRITE $(2,101)$

W'RITE $(2, J 18)(I, P(I), I=1, N P)$. 
PACE NC.

I:F.TTE $(2,30)$

2 I PACE $=$ IPACE + I



B.RITE $(2] C,, \pi)$

VIITE $(2,1] S)$

VRITE. $(2,103)$

P.RJTF $(2], C),(I, Y(I), J=1, N Y)$

VFITE $(2,3(1)$

VRITE $(2,12])$

VRTTE $(2,10 \mathrm{~J})$

VFITE. $(2,322)(I, X(I), I=1, N ! X)$

V.P.ITE $(2,1 \cap 1)$

VIRTTE. ( ?, IRI)

I PACE = IPACF + I

VRITE $(2$, J TC) (ID (I), I = , ? ), IRUN, I TACE

V:RITF ( 2, JRI)

V'FITE (2, 135)

W:FITE $(2,3) ?$ ?

V.FITE (2, ]24)P(2), $\Gamma(1), F(5)$

WFITF $(2,325) P(5), P(7), F(0)$

PRITE $(2,125) P(1 r), P(1\}), P(1 A)$

WRITF $(2,327) P(12)$

hiFITF. (2, 123)

HFITE $(2,135)$

IF (ND (J O) . E.S.C.ANT. IRUN. FO.J)RETIRN

WRITE $(2, j \cap])$

WRJTE $(2,336)$

VITITE $(2,132)$

VRITE $(2,13])$

WRITE $(?] ? 2$,

URITE $(2,13 ?)$

VRITE $(2,1 ? ?)$

WRITE $(2,132)$

V:FITE $(2,3 ? 5)(R A M P(I), \operatorname{STPT}(I), T I M(I), I, I=1, N S E C)$

I.PITE $(2,12 ?)$

IPACEE = IPACE + I

RETIIRN

E.ND

SUR.RCUTINE INIFUN

C

C

C

INITILIZ.F FUNCTION SURPOUTINE.



COMMCN/FP/XSTR $(1,50), X T(9), X T H(9)$, IH (O) , NH, JMAX, H(O)

C CMMCN/GC/N $/ 2 r), N P T, N S P, N T M$, PTIMF, ISW

COMMCN/HH/RTIMF, F.TIME, I.ELT, IT J (IC), JT 2(]$C), M T(3), M N(3), J D(3), M S(3)$

C COMMON/I I/I SAMP, NTIMF, NDY, JNY, CII $(20), C D O$

C

1 CO FORMAT (1H!1,5X,23H** TIME [FLAY VARIAPLE, I 1, 18H EXCEFDS THE MAXIM, * 4 SHUM ARRAY SIZE VIHEN IIVIDET BY DELT RGM STOP **/)

C

$\operatorname{IMAX}=0$

IF (NH.EC.R) GO TC 3 
PACE NO. J J

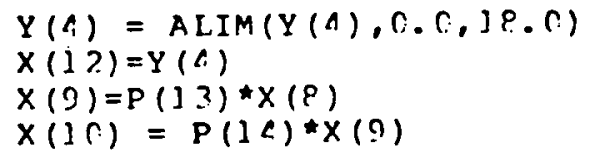

C

RETURN

ENT

FUNCTION $\operatorname{ALIM}(V, P, T)$

$A L I M=V$

IF (V.CT.T) ALIM $=T$

$I F(V . L T . E) \quad A L I M=B$

RETURN

ENT:

SURRCUTINE SPATJ

C

COMMON $/ M A / X(5 C), F(4 \cap), Y(2.2), Y T(2), F(1 \Omega), C(O), N Y, N X, N F, M M S P$

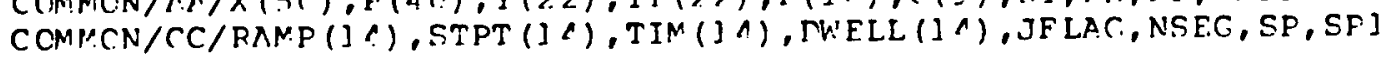

$C$ THIS IS THE SET POINT ADJUSTMFNT ROUTINE. THE. RECIPE IS REAI IN

C FROM SURECUTINE RFCIPE. SOME CF THF. FEATURES OF THE ROUTINE ARE:

C ... J) NO RAMP MAY BE SPECIFIEN IN SECMENT 1.

6 ... 2) MUELL PERICIS ARF. IN SECONIS AND AFPLY TO THF. SPECJFIES

C SFCMENT ONLY.

C... 2) THE SET POINT IN ANY SECMENT FXCEFT I MAY RE SFECIFIET AS $Z$ ERC

C ANE THAT SECMENT VIIL USE THE PRECEDINC SEGMENTS SET POINT.

C... 4) TWO CONSECUTIVE SECMENTS MUST HAVE $A T$ LEAST ONE SET POINT

C... E) THECIFIER.

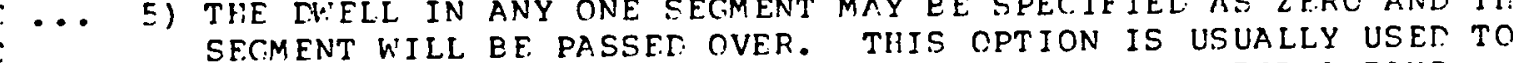

SPECIFY A DIFFERENT SET POINT AS A START POINT FOR A RAMP.

... 6) A TWELL MUST BE SPECIFIET IN A RAMP SECMENT.

C... 7) NO TWO CONSECUTIVE SEGMENTS MAY BE SPECIFIED WITH A 2 ERO DW'ELL

... 8) POSITIVE RAMPS ARE TEFINET. BY A PLUS CR NO SIGN BEFORE THE

RAMIP RATE MACNITUEE.

C... C) DOH'N RAMPS ARF LEFINET BY A NECATIVE SIGN BEFORE THE RAMP

RATE. MACNITUDE

C... 30) A RAMF SECMENT MUST HAVE SPECIFIEI A RAMP RATF, A. TERMINATION

$c$ SET POINT, ANI $A$ TERMINATION TIME LIMIT. THAT TIME LIMIT MAY BF. SPFCIFIED GREATER THPA THE ACTUAL RAMP TIME.

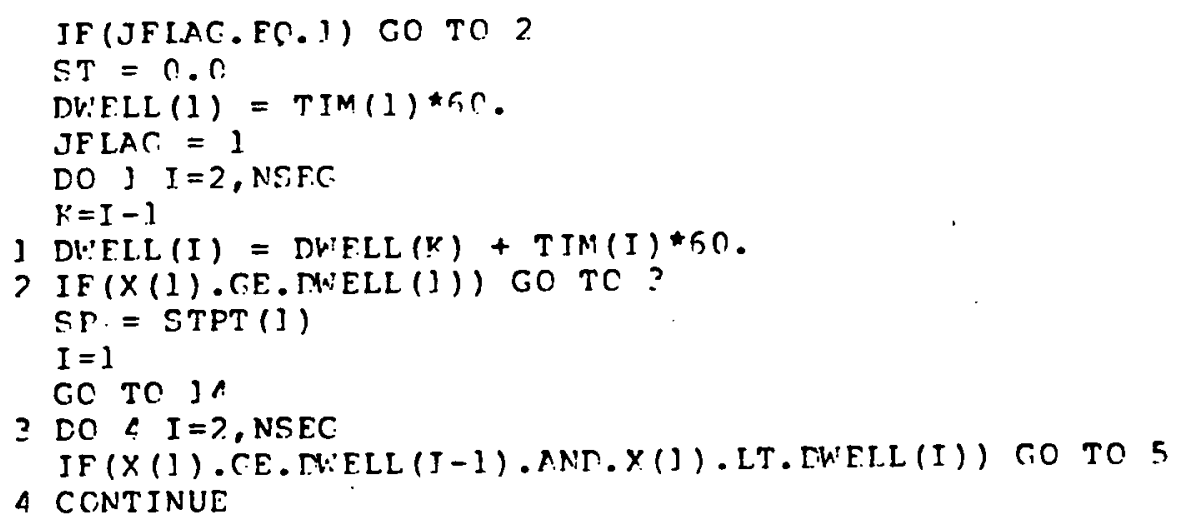


PAGE NO. 12

\section{RETURN}

5 IRAMP $=$ RAMP (I)

IF (IRAMP.NE. O) GO TO 6

GO TO 7

$6 \mathrm{BT}=\operatorname{DWELL}(I-1)$

$S L P=R A M P(I) / F C$.

$S P=S L F *(X(1)-B T)+\operatorname{STFT}(I-I)$

IF (STPT (I-1).LT. S0.) SP $=\operatorname{SLP*}(X(1)-R T)+\operatorname{STFT}(I-2)$

IF (ARS (SP-STPT (I)) . LT.R.S.ANR.Y(J).LT.DWELL(I)) CO TO 12

IF (RAMP(I) . LT. R.S.) GO TO IJ

GO TO 10

7 SP $=$ STPT (I)

$S P=\operatorname{STPT}(I-1)$

IF (I.CT. 2) GO TO R

GO TO 14

8. $\mathrm{CH}=\mathrm{SP}-\mathrm{STPT}(\mathrm{I}-2)$

IF ( $\mathrm{CH} . \mathrm{LT} . \mathrm{N} . \mathrm{C})$ GO TC 11

GO TO 10

$9 \mathrm{CH}=S P-S T P T(I-1)$

IF(CH.LT.C.O) GO TC II

$10 \mathrm{PI}=\mathrm{P}(12)$

$P 2=P(13)$

$P 3=0.0$

CO TO 14

$11 P]=P(12)$

$P 2=P(13)$

P3 $=0.0$

GO TO 14

$12 A D T=D H E L L(I)-X(1)$

$S P=\operatorname{STPT}(I+I)$

IF (SP.LT. SO.) SP=STPT (I)

DWELL (I) = DWE.LL (I) - A.TT

IF (SP.EQ. STPT (I-1)) CH $=\operatorname{SF-STPT.(I-2)~}$

IF (CH.LT.r.R) GO TO 1$]$

$\mathrm{CH}=\mathrm{SP}-\mathrm{STPT}(\mathrm{I}-1)$

$I=I+1$

IF (I.CT.NSEC) GO TO 14

DO $13 \mathrm{~K}=\mathrm{I}$, NSEC.

$13 \operatorname{DWELL}(K)=\operatorname{DWELL}(K-1)+\operatorname{TIM}(K) * 5 n$.

Go To in

$14 \quad x(2)=x(2)$

C

$x(3)=x(3)$

MMSP $=I$

RETURN

END

SUBROUT INE TELAY

C THIS SUBROUTINE SETS UP THE DELAY PIPELINES.

C CCMMON/BB/XSTR $(1,5 n), X T(Q), X T H(Q)$, IH (O),NH, IMAX,Y Y (O)

c.

ISTOP = IMAX - 1

DO I KK=1, ISTOP

$I S=I M A X-K K$ 
FACE NO. 1?

$J S=I S+I$

CC J II $=1, \mathrm{NH}$

c

$1 X S T R(I I, T S)=X S T R(I J, I S)$

C

$\Gamma C>I I=J, \mathrm{AH}$

$J J=I H(I I)$

$X T H(I I)=X S T R(I I, J J)$

$2 \times \operatorname{XTR}(I I, 1)=X T(I I)$

RFTURN

ENT.

SUEROUTINE IIFEES

C

C . . TIFFFRENTIAL ECUATION ROUTJNe.

c

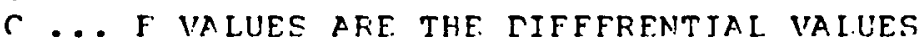

c.

COMNCN/AM/X (5C),P(An),Y(22), YT (2?),F(In),C(O),NY,NX, NP, MMSP

WiN $=P(7) * P(7)$

$F(3)=P(5) * X(4) / P(5)$

$F(2)=Y(1) * 1 * N-2 * * P(7) * P(8) * Y(2)-W N * Y(3)$

$F(3)=Y(?)$

$F(C)=x(8)$

$\Gamma(5)=x(3) * x(3)$

$F(5)=A E S(X(?))$

C.

[O J $L K=1, N Y$

$I S=N Y+2+L K$

c.

$1 Y(I S)=F(L Y)$

RETURN

ENT.

FUNCTION: FOL (GA, XIN, YOUT, TAU)

IF (TAU.NE.C.R) GO TO I

YOUT $=$ GA*XIN

$F C L=n$. ?

RETUPN:

] $F O L=(C \lambda \star X I N-Y O U T) / T A U$

RETIIRN

END

SURROUT INE RKINT (LL)

$c$

C RINGE-KUTTA NUMERICAL INTEGRATION ROUTINE FCR SOLVING DIFFERENTIAL

C FSUATIONS.

C

C

COMMCN/AA/X (5C),P(AC),Y(2.2), YT (2.2), F(JC), C (9), NY, NX, NP, MMSF

C

DIMENCION YU (A?), PET (?), RY $(1,2 n)$

DOURLE FRECISION YU

IF (LL.NE.J) GC TO J

BET (l) $=0.5$

$\operatorname{BET}(2)=0: 5$

$\operatorname{BET}(3)=1 . C$

$\mathrm{N} 2=\mathrm{NY}+2$ 
PAGE NO. 14:

$$
\begin{aligned}
& N]=N Y+J \\
& X V=Y(N J) \\
& \text { CALL TIFFES }
\end{aligned}
$$

] DO 2. $I=1, N Y$

$2 Y U(I)=Y(I)$

DO \& $K=1, \wedge$

IF (K.ES.J) GC TO ?

CALL LIFEEC

3 DO \& I =1, NY

$I J=I+N 2$

$\triangle D Y(K, I)=Y(N 2) * Y(I J)$

IF (K.ES.Q) GO TO ?

.DO $5 I=1, N Y$

$5 Y(J)=Y U(I)+\operatorname{RET}(K) * D Y(K, J)$

$Y(N])=X V+P . E T(K) * Y(N 2)$

6 CCNTINUE

IO $7 I=1, N Y$

$D E L=(D Y(1, I)+2 . * D Y(2, I)+2 . * D Y(?, I)+\Pi Y(\Lambda, I)) / \pi$.

$Y U(I)=Y U(I)+D E L$

$Y(I)=Y U(I)$

7 CONTINUE

$Y(N I)=X V+Y(N ?)$

CALL LIFFES

$X V=Y(N 1)$

RETURN

END

c

SUBROUT INE PRTTRL (MAXLIN, IV)

C THIS ROUTINE PRINTS THE SPECIFIEI TAPLIS.

C

COMMCN/DD/ITY, ITX, ICY, IGX, NC, SE (I 2), FL, PR, IRUN, I IACE, IX, IY, NCUT COMMCN/EF/XG $(R, 2), Y C(8,2), M S S, N C Y(8), N C X(P), N T Y(P), N T X(8)$

COMMON/FF/IARJ, MX, MY, JX (8), JY (P),XS $(90], 8), Y S(O \cap], 8)$

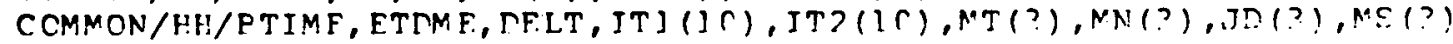

COMMCN ARY $(901,8)$, NPRT (8)

C

C

FCRMAT(1H], 6X, DTHHYDRAULIC SPEET CONTECL ?OS TCN HFM FAM CLOSINC,

$1] 3 \mathrm{H} *$ RUN DATE , 3A , $2 X$, PIIRUN NC. II, $2 X$, SHFACE NC, ,I?/)

IกI FCRMAT $(8(7 x, \lambda], \lambda],. I 2, A], 2 X))$

$1 \cap 2$ FORMAT $(8(2 X, \Gamma] 2 . \wedge))$

c

Iก3 FCRMAT $(1 X, 120(1 H *) /)$

C

IF (IV.EC. C)GO TO ?

$\mathrm{IB}=\mathrm{IX}$

$\mathrm{NCOL}=I T X$

DO I I $=1$, MAXLIN

DO I $J=1, N C O L$

I $\operatorname{ARY}(I, J)=X S(I, J)$

DO $2 I=1, N C O L$

2 NPRT(I) $=$ NTXII)

GO TO 6

$3 I B=I Y$

NCOL $=$ ITY 


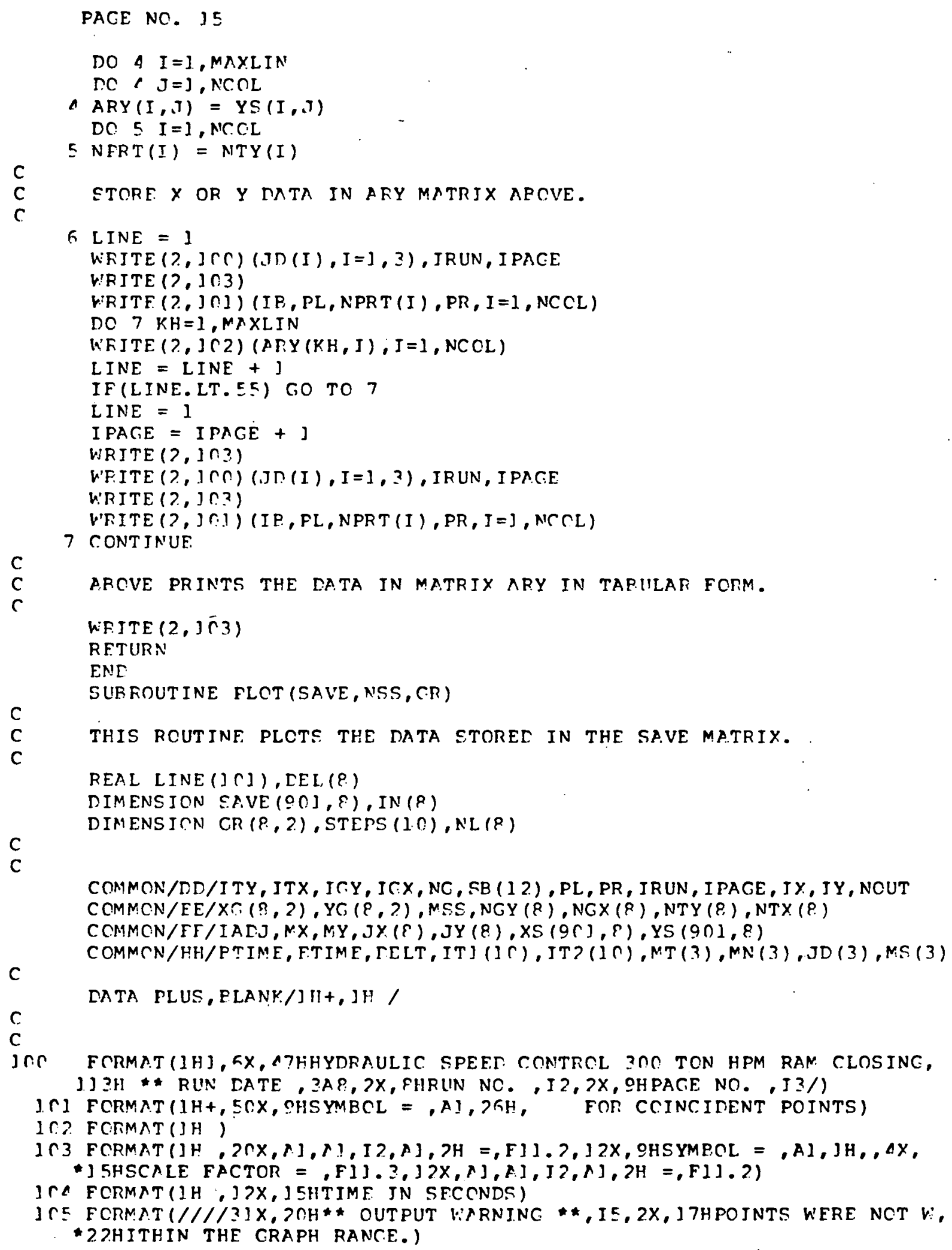




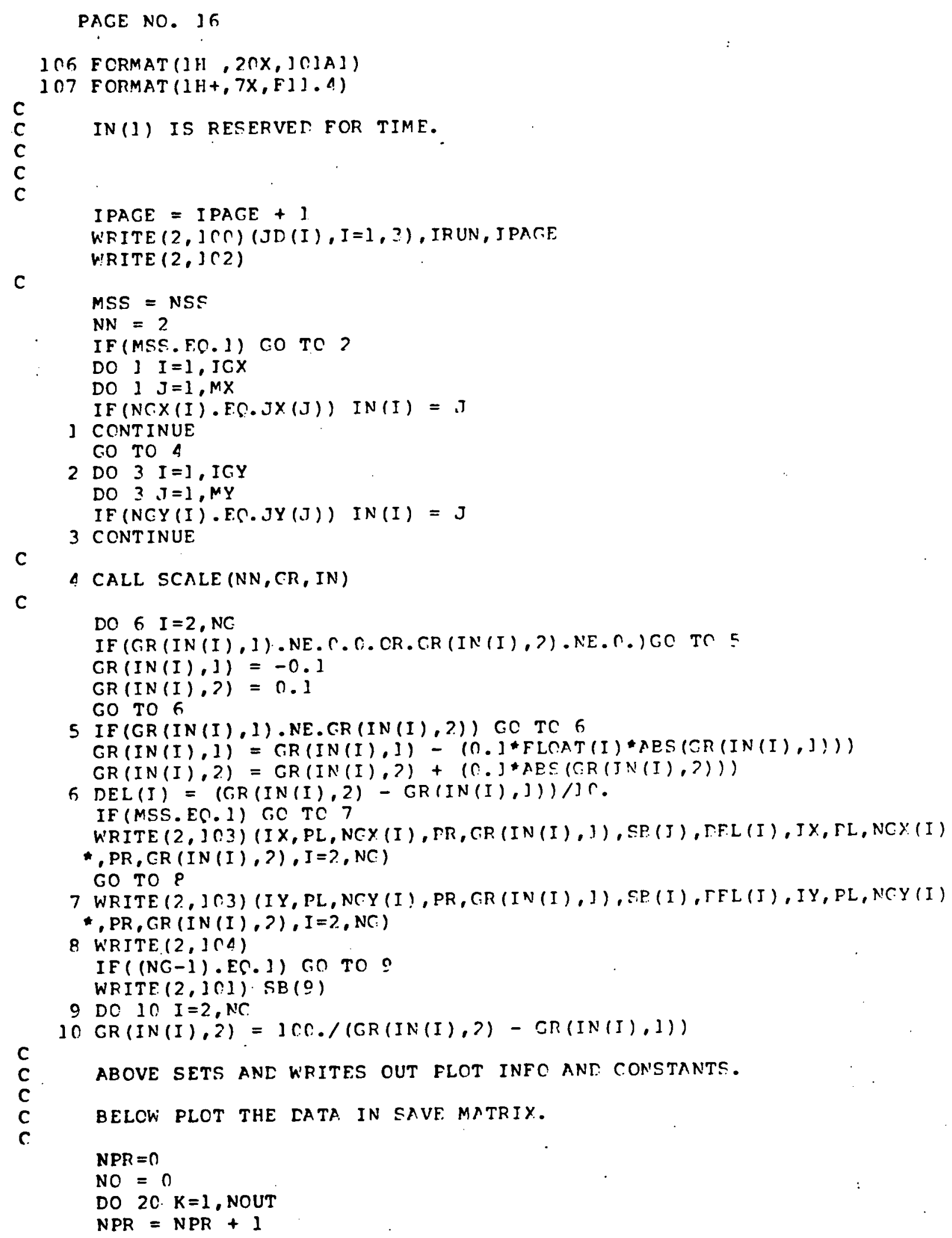


PACE NO. J?

IF (K.NE. . ANE.Y.NE.NCIT) GO TC I].

$N F R=5$

$1]$ IF (NKR. NE. F) GC TO 12

DO $12 \mathrm{I}=\mathrm{J}, \mathrm{J} \mathrm{CJ}$

12 LINF. I $=$ PLIIS

GO TC J6

$1 ?$ DO IA $I=2,16 \mathrm{C}$.

16 LINE(I) = PLANK

DO $] 5 \quad I=3, J[1]$,

15. LINF. (I) = PLUS

J 6 DC J $9 I=2, N C$

$N=\operatorname{IFJX}((\operatorname{SAVE}(K, I N(I))-G R(I N(I), J)) * G R(I N(I), 2)+1.5)$

IF (N.CE.J.AND.N.IF.ICI) GO TO 17

$\mathrm{NO}=\mathrm{NC}+1$

GC TC 19

17 IF (LINE(N) EES.FLANK. CT. LINE(N) E FS. FLUS) GO TO IR

$\operatorname{LINE}(N)=\operatorname{SP}(C)$

GC TC 1 ?

If LINE. (N) $=\operatorname{SB}(\mathrm{J})$

1? C.CNTINUE

VIFITF. $(2,1 C 5)$ LINE

IF (NPR.NF. S) GO TO 20

WRITE (2, 1ח?) SAVF. (K, IN (1))

$\mathrm{NPR}=n$

5R CONTJNUE.

IF (NO.NE.R.) VRITE. (2,IRS) NO

2.1 RETURN

ENL.

SUBRCUTINE SCALE (J.T, CR, JC:

$c$

C

THIS RCUTINE SCALES THE DATA FCR PLOT LIMITS.

CCMMCN/DD/ITY, ITX, ICY, ICX, NG, SB (1 2) , PL, FR, IRUN, I PACE, IX, IY, NOUT CCMMCN/SC/NI(2N), NFT, NSF, NTM, FTIME, ISW

C

IIMENSION GR $(8,2)$, STEPS (]$r)$, JC ( $(8)$

DIMENSICN SCR $(R, 2)$

C

LNTA STEPS/1.,2,.3.,4.,5.,6.,7.,8.,.,.10./

C

JOC FCRMAT (2F]r.C)

C

IF (NI. (O).ES.Q.) GO TO 15

IF (NI. (g) . E.S.R) CO TC 7

IF $(N D(9)$. ES. 2$)$ GO TO 3

IF (ND (?). F. ? ?) GO TO 1

REAL (1, J RC) YMIN, YMAX.

GO TO 5

1 DO $2 \quad I=2, N G$

REAT $(1, J$ J IYM JN, YMAX

$\operatorname{SGR}(J G(I), J)=Y M I N$

$\operatorname{SCR}(J G(I), 2)=$ YMAX

$G R(J C,(I), 1)=Y M I N$

2. $\operatorname{GR}(J C(I), 2)=\operatorname{YMAX}$

RETURN 
FACE NO. 18 .

C

$3 Y M I N=G R(J G(2), J)$

YMAX $=G R(J G(2), 2)$

IF ( $(\mathrm{NC}-1)$. F.S. 1$)$ GO TO 7

c

IO $\cap I=J J, N C$,

IF(YMIN.CE. CR (JC(I),J)) YMIN $=\operatorname{GR}(J C,(I), J)$

IF (YMAX.LE.GR (JC(I), D)) YMAX = CR(JC(I), , )

4 CCNTINUE

5 DO $F I=J \mathrm{~J}, N G$

SGR (JG(I), J) = YMIN

$\operatorname{SGR}(J G(I), 2)=$ YMAX

$G R(J C(I), 1)=$ YMIN

C

G $C R(J C(I), 2)=\operatorname{YMAX}$

C

IF (ND(9) . E.. J . CR.ND(9) . F.S. 2) RFTURN

7 DO $14 \mathrm{~K}=\mathrm{JJ}, \mathrm{NG}$

$Y M I N=G R(J G(Y), J)$

YMAX $=$ CR (JG(K), 2)

$D Y=($ YMAX - YMIN) $/ 1 C$.

JF (DY.LE.N.C) GC TC JA

$T A=A L O S J C$ (DY)

$I R=T A$

IF (TA.LT.R.R) IR = TA. -1 .

$L Y=D Y * 10_{0 *}^{*}(-I K)-0.0 \Gamma E$

DO \& $\mathrm{J}=1,1 \mathrm{C}$

IF(STEPS (J). IT.DY) GC TC P

$I=J$

CO TO ?

8 CCNTINUE

$I=10$

CONTINUE

IF (I.LE.JC) GO TC IN

$I=I-10$

$I R=I R+1$

IS CONTINUE

COR $=$ STEPS $(I) *] r_{*} *$ IR

IF (I.EC.IC) IR=IR+I

IF (YMIN.CE.r.R) COTR JI

$M I N=Y M I N / C C R-.0 n 5$

CO TO J?

1) CONTINUE

MIN $=$ YMIN/COR + . ROE

12 CONTINUE

$T A=M I N * C O R$

$T R=T A+1 C \cdot * C R$

IF (TR.GE. YMAX) GO TO 13

$I=I+I$

GO TO

$13 \operatorname{GR}(J G(K), 1)=T A$

$\operatorname{GR}(J C(K), 2)=T R$

$\operatorname{SGR}(J C:(K), J)=T A$

$\operatorname{SGR}(J G(K), 2)=T B$

14 CONTINUE 
PAGE NO. IS

RF.TURN

J5 DC J $I=. T J$, NC.

$\operatorname{GR}(J C(I), J)=\operatorname{SCR}(J C,(I), J)$

J G GR (JG (I), 2) = SCR (JC:(I), 2)

RETURN

END

C

SUR RCUTINE. FARATS



C DIMENSICN NPA $(2 n)$

C

$1 \operatorname{FCRMAT}(2 \cap(I 2,1 X))$

2. FCRMAT (I 2)

C

3 FORMAT (F.FJC.R)

c.

REAT $(1,2)$ JP

$\operatorname{RE} \Gamma(1,1)(N \Gamma \wedge(J), J=1, . J P)$

RFAL(], I) (P (NPA (J)), J = J, JP)

c

RETURN

FND

C

BLOCK DATA

COMMCN/DE/ITY, ITY, ICY, ICX, NC, SP (I Z), FL, FR, TFLIN, IFACE, IY, IY, NCUT

C

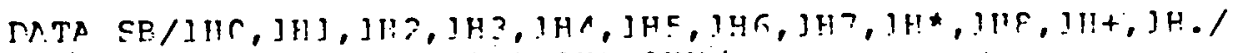

DATA. FL, PR, IX, IY/IH(,JH),JHY,JHY/

$c$

ENS 
BDX-613-2483

SPEED AND PRESSURE CONTROL SYSTEM DESIGN AND SIMULATION FOR A COMPRESSION PRESS, R. H. Floersch, Topical, April 1981.

A new system design using closed loop control on the hydraulic system on compression transfer presses used to make filled elastomer parts will improve accuracy and repeatability of speed and pressure control during critical pre-cure forming stages. The present open loop system does not provide the control necessary to mold repeatably the filled elastomer products. These products form with great difficulty because of high loading levels of filler materials. The new system will

PLASTICS: Molding

SPEED AND PRESSURE CONTROL SYSTEM DESIGN AND SIMULATION FOR A COMPRESSION PRESS, R. H. Floersch, Topical, BDX-613-2483, April 1981.

A new system design using closed loop control on the hydraulic system on compression transfer presses used to make filled elastomer parts will improve accuracy and repeatability of speed and pressure control during critical pre-cure forming stages. The present open loop system does not provide the control necessary to mold repeatably the filled elastomer products. These products form with great difficulty because of high loading levels of filler materials. The new system will

SPEED AND PRESSURE CONTROL SYSTEM DESIGN AND SIMULATION FOR A COMPRESSION PRESS, R. H. Floersch, Topical, BDX-613-2483, April 1981.

A new system design using closed loop control on the hydraulic system on compression transfer presses used to make filled elastomer parts will improve accuracy and repeatability of speed and pressure control during critical pre-cure forming stages. The present open loop system does not provide the control necessary to mold repeatably the filled elastomer products. These products form with great difficulty because of high loading levels of filler materials. The new system will 
mean improved wall thickness and control of loaded elastomer parts, thus reducing the amount of scrap caused by wall thickness variations.

mean improved wall thickness and control of loaded elastomer parts, thus reducing the amount of scrap caused by wall thickness variations.

mean improved wall thickness and control of loaded elastomer parts, thus reducing the amount of scrap caused by wall thickness variations. 